Florida International University FIU Digital Commons

$3-27-2006$

\title{
Nursing faculty intention to use service learning as pedagogy in higher education
}

Margaret Bagnardi

Florida International University

DOI: $10.25148 /$ etd.FI14050406

Follow this and additional works at: https://digitalcommons.fiu.edu/etd

\section{Recommended Citation}

Bagnardi, Margaret, "Nursing faculty intention to use service learning as pedagogy in higher education" (2006). FIU Electronic Theses and Dissertations. 1369.

https://digitalcommons.fiu.edu/etd/1369 
FLORIDA INTERNATIONAL UNIVERSITY

Miami, Florida

NURSING FACULTY INTENTION TO USE SERVICE LEARNING

AS PEDAGOGY IN HIGHER EDUCATION

A dissertation in partial fulfillment of the

requirements for the degree of

DOCTOR OF EDUCATION

in

HIGHER EDUCATION

by

Margaret Bagnardi

2006 
To: Dean Linda Blanton

College of Education

This dissertation, written by Margaret Bagnardi, and entitled Nursing faculty intention to use service learning as pedagogy in higher education, having been approved in respect to style and intellectual content, is referred to you for judgment.

We have read this dissertation and recommend that it be approved.

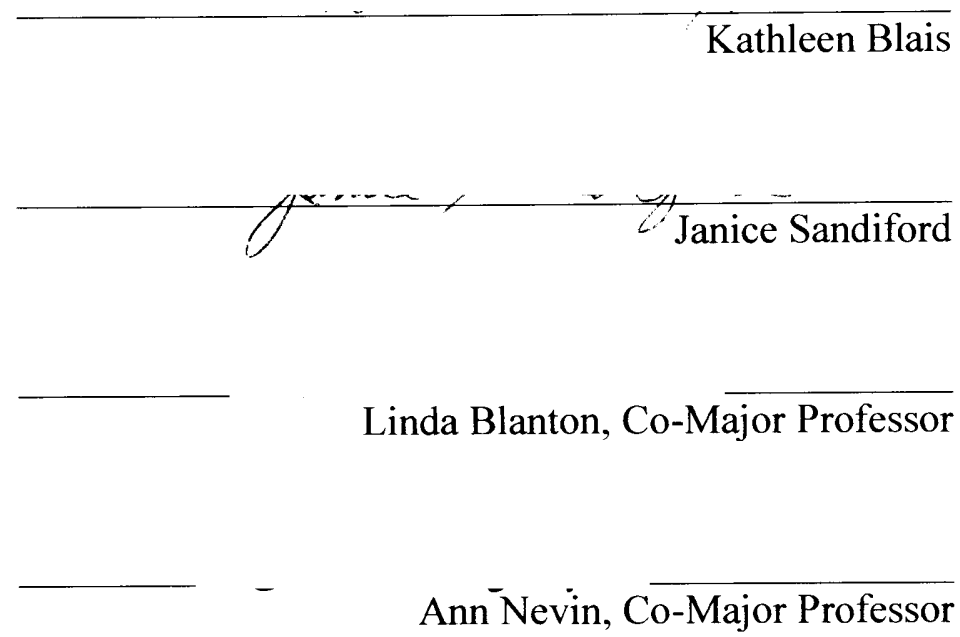

Date of Defense: March 27, 2006

The dissertation by Margaret Bagnardi is approved.

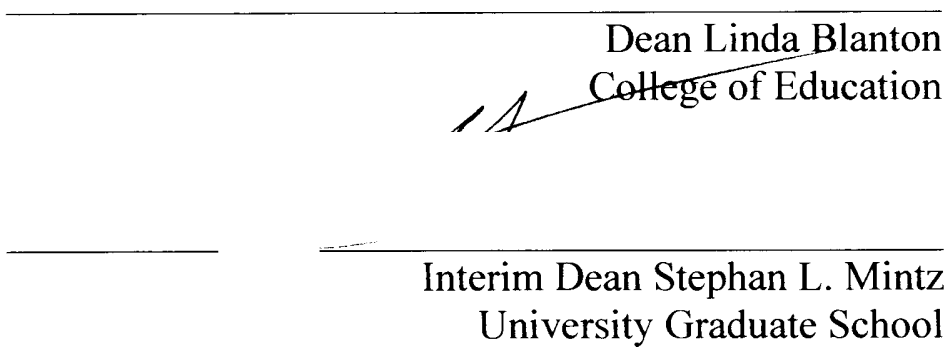

Florida International University, 2006 


\section{ACKNOWLEDGMENTS}

I would like to extend my extreme gratitude to the members of my committee for their guidance and support through the dissertation process. I would never have gotten through this without their encouragement and amazing expertise. To Dr. Sandiford who has been my advisor throughout the program and who has gone out of her way to facilitate my progress through the program. Her annual dissertation boot camp experience provided a community of scholarship for students, which I benefited from enormously. To Dr. Blais, who was one of my primary professors during my undergraduate education at FIU; her encouragement to continue my education will always be appreciated. I would like to thank Dr. Blanton, whose willingness to work with me has been an invaluable experience. To Dr. Nevin, who spent many hours guiding and supporting me, but who also always found time to acknowledge the tiny accomplishments I made along the way and celebrated them with enthusiasm.

Finally, I would like to thank my friend and colleague Dr. Jessie Colin for many long discussions on higher education and scholarship, and who was always a calm, supportive friend when work and school became hectic for me. 


\author{
ABSTRACT OF THE DISSERTATION \\ NURSING FACULTY INTENTION TO USE SERVICE LEARNING \\ AS PEDAGOGY IN HIGHER EDUCATION \\ by \\ Margaret Bagnardi \\ Florida International University, 2006 \\ Miami, Florida \\ Professor Linda Blanton, Co-Major Professor \\ Professor Ann Nevin, Co-Major Professor
}

The purpose of this study was to identify the factors that motivate nursing faculty to use service learning. The study was based on the theory of planned behavior (TPB), which implies that the target behavior of intention to use service learning in higher education is influenced by the predictor variables of behavior beliefs (attitude), normative beliefs (peer influence), and control beliefs (confidence and resources). External variables were also considered (years of teaching experience, tenure status, and the type of curriculum).

Group interviews and a pilot test were conducted to create the instrument for the study, and Cronbach alpha were calculated for survey item reliability. The participants were full time undergraduate nursing faculty members $(n=160)$ in the Southeastern United States who taught in universities with accredited nurse education programs. Demographic data as well as scores on scaled survey responses were used to evaluate the intention of nursing faculty to use service learning in their classes. 
Pearson product moment correlation coefficient and path analysis were applied to the data. The correlation findings indicated that there were statistically significant relationships between behavior beliefs, normative beliefs, and control beliefs and nursing faculty intention to use service learning. The path analysis also indicated that behavior beliefs and normative beliefs were significant, while control beliefs were not a strong influence on intention to use service learning. Normative beliefs showed the strongest direct influence. The use of a community based curriculum also had a positive influence on intention, and faculty with tenure status were more likely to have positive behavior beliefs (attitude) towards service learning. Finally, as teaching experience increased, positive attitudes towards the intention to use service learning decreased. Seventy-nine percent of the variation in the intention to use service learning was explained by the theory of planned behavior, the type of curriculum, teaching experience, and tenure status. These results will assist nursing administration and faculty to design strategies to facilitate the implementation of service learning pedagogy, as weIl as a community based curriculum which will help meet the $21^{\text {st }}$ century goals set forth from the American Association of Colleges of Nursing. 


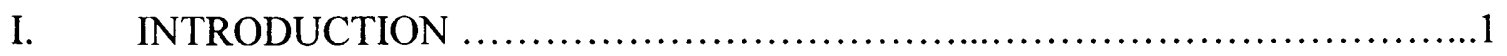

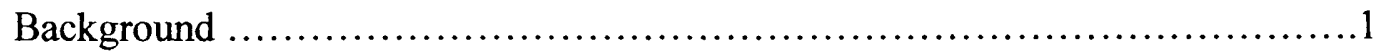

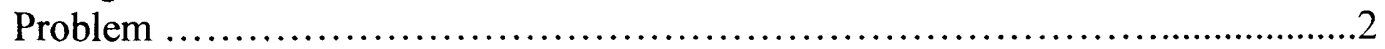

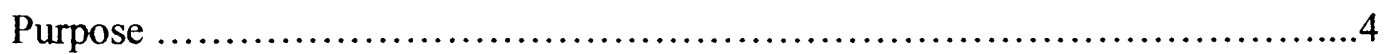

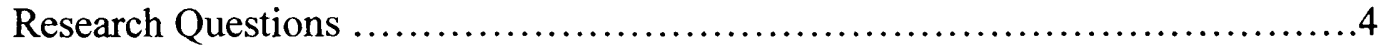

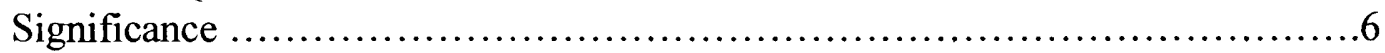

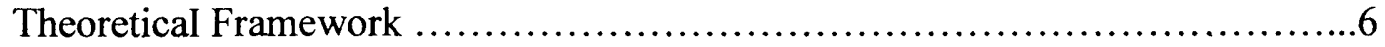

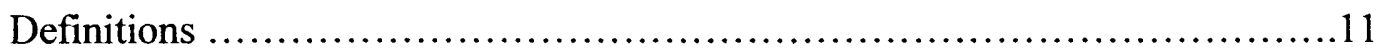

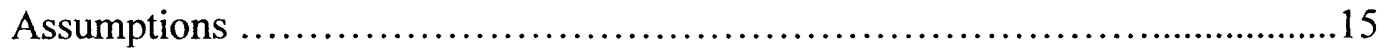

Overview of Chapters .................................................. 17

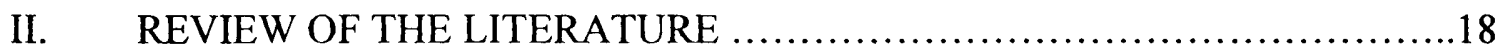

Research on Faculty Motivation .............................................19

Faculty Motivation to Use Service Learning ...............................22

Theory of PIanned Behavior ............................................. 31

Nursing Education ........................................................

Discussion ...............................................................

Summary of Chapter Two ...............................................43

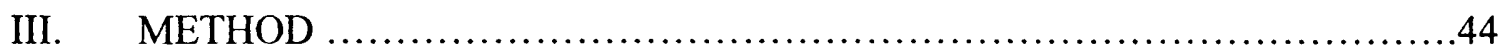

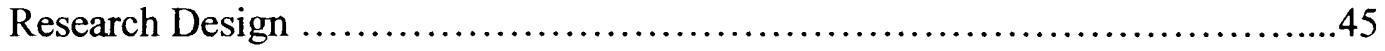

Sample and Setting ......................................................46

Instrument Development ...............................................49

Procedure for Protection of Human Subjects .................................56

Data Collection ..........................................................56

Procedure for Survey Data Analysis ......................................58

Summary of Chapter Three .............................................60

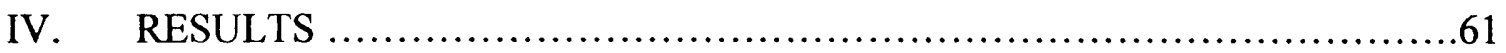

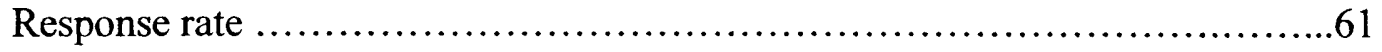

Participants ............................................................61

Pearson Product Moment Coefficient Correlation .............................64

Path Analysis .........................................................67

Summary of Chapter Four ............................................... 75

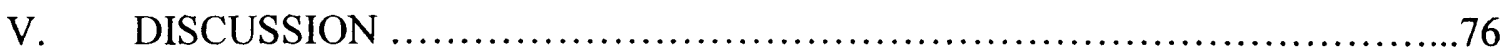

Evaluation of Study Results............................................. 77

Discussion of Results ................................................ 78

Revisiting Assumptions ................................................ 85

Limitations of Study .................................................. 86

Implications for Nursing and Higher Education ............................88 
Recommendations for Future Research

Conclusions

REFERENCES

APPENDICES

102

VITA 


\section{LIST OF TABLES}

TABLE

PAGE

Table 1. Studies of institutional support and faculty motivation to use alternative pedagogy

Table 2. Studies of faculty motivation to use service learning 23

Table 3. Studies of institutional factors and the use of service learning .28

Table 4. Studies of the theory of planned behavior in various disciplines 32

Table 5. Type of curriculum for participating universities 48

Table 6. Teaching experience of survey respondents

Table 7. Demographic characteristics of survey respondents .63

Table 8. Correlation analysis of theory of planned behavior constructs

Table 9. Path coefficients in standard form for the model variables. 70

Table 10. Path coefficients in unstandardized form .73 


\section{LIST OF FIGURES}

FIGURE

PAGE

Figure 1. Conceptual model of proposed relationship among TPB constructs and tenure, curriculum, and experience

Figure 2. The theory of planned behavior applied to nurse faculty motivation to use service learning pedagogy

Figure 3. Path model for nurse faculty intention to use service learning .68

Figure 4. Indirect paths associated with behavioral beliefs and behavior intention .71

Figure 5. Indirect paths associated with normative beliefs and behavior intention .75

Figure 6 . Indirect paths associated with control beliefs and behavior intention .75 
CHAPTER I

\section{INTRODUCTION}

Nursing faculty often struggle to find ways to incorporate a sense of civic responsibility in students, provide service to the community, and prepare students for professional nursing practice. Service learning is a pedagogical approach that facilitates these attributes (Astin \& Sax, 1998; Bringle \& Hatcher, 1995, 1999; Driscoll, 2000). Despite research that shows service learning is an effective teaching pedagogy (Astin \& Sax, 1998; Gelmon, Holland, Seifer, Shinnamon, \& Connors 1998), there appear to be barriers to its use by many nursing education faculty. Several researchers have described barriers to the use of service learning as pedagogy in higher education, including issues related to the faculty merit system for promotion and tenure, faculty complacency, lack of administrative support, prior experience with community service, and personal beliefs and attitudes (Grey, Ondaatje, Fricker, \& Geschwind, 2000; Hammond, 1994; Hayden, 2004; Ward, 1998). Despite the benefits to students that have been described in the research, the use of service learning as pedagogy by nursing faculty in higher education has been reported sporadically and inconsistently in the literature.

\section{Background}

Many institutions of higher education include service as a part of their mission and have a genuine awareness of the need to provide service to the community to actualize this pillar of their mission statements (Astin \& Sax, 1998; Boyer, 1990). Today, there are also conflicting viewpoints concerning the value of service in tenure and promotion consideration, as well as how service is defined and emphasized at a professional and university level. Boyer (1990) reported on these shifting priorities in 
higher education, emphasizing the quandary between the professorial role of teacher, researcher, and community service provider. He described a dichotomy between the scholarship expectations of administration and faculty, which often creates a strain in the higher education work setting. These issues often lead to problems for each faculty member when it comes to balancing demands for scholarship, curriculum development, and pedagogical choices.

Nursing education and practice have changed over the past century with a distinct shift from a hospital based diploma education to that of a formal degree granting, college level program. In nursing practice, the first nurses worked in the home and community environment, but as the United States moved into the $20^{\text {th }}$ century, there were political and social influences that shifted nursing practice from the community into the acute care environment. These changes occurred because of wars, technological advances, and economic trends in this country (Hunt, 2002). However, there now appears to be a shift back towards the community setting for nursing education and practice.

The shift from hospital based nursing curricula to community based curricula necessitates reconsideration of pedagogical choices. Faculty are challenged to reform their current practices to meet the standards set forth by accrediting agencies such as the American Association of Colleges of Nursing (AACN). For nursing faculty, the choices they make in curricular and classroom situations can make a difference in the quality of the educational experience.

\section{Problem}

Higher education faculty face challenges such as role strain between researcher, teacher, and community service-provider. The ability to balance these professorial roles 
effectively is influenced by many variables. These variables include intrinsic factors such as personal beliefs and attitudes about their own philosophy of teaching, their preferences for pedagogical approaches, and extrinsic factors such as peer pressure, administrative support, and available resources.

In 1999, the American Association of Colleges of Nursing (AACN) issued a position statement entitled Nursing Education's Agenda for the $21^{\text {st }}$ Century, which emphasized the integration of service and learning into the mission statements of schools of nursing. AACN (1999) recommended that the nursing curriculum be restructured toward the immediate and global community. This represents a significant paradigm shift from the hospital based curriculum that currently prevails. In order to move toward this vision for a community based curriculum, nursing faculty may need to adapt their teaching strategies in the classroom and clinical settings.

Service learning has been discussed at length in the nursing literature as a means for meeting the $21^{\text {st }}$ century goals of nursing education (Cohen \& Milone-Nuzzi, 2001; Hunt, 2002; Seifer \& Vaughn, 2002). There is extensive research on the effectiveness of service learning on student learning and personal growth (Astin \& Sax, 1998; Driscoll, 2000). However, research on the motivational factors that influence the use of service learning by educators has been sparse in the area of education specialties, especially nursing education. The study of nursing faculty brings a new perspective of service learning as a pedagogical approach in programs that consistently have clinical experiences outside the classroom. Eliciting the motivational factors and deterrents to the use of new pedagogy in nursing curricula may also provide insight into the pedagogical changes in nursing education. 


\section{Purpose}

The purpose of this study was to identify the factors that motivate nursing faculty to use service learning pedagogy. Throughout the $20^{\text {th }}$ century, political, social, and environmental influences have shaped the profession of nursing, leading to the position statement made by the AACN in 1999. In response, many schools of nursing have changed their curriculum to a community-based curriculum, and service learning has been discussed at length in the nursing literature as a means for meeting the $21^{\text {st }}$ century goals of nursing education (Berkowitz, 2002; Cohen \& Milone-Nuzzi, 2001; Hunt, 2002; Seifer \& Vaughn, 2002). The empirical research to actualize these objectives and goals is sparse, and the paradigm shift in curricular focus from the hospital to the community has not provided sufficient impetus to motivate faculty to use service learning pedagogy.

The theoretical foundation for this study was the theory of planned behavior (TPB) by Ajzen (1991). TPB is a motivational theory that measures behavior intention using three belief constructs (behavioral beliefs, normative beliefs, and control beliefs) that has been used in prior research on faculty motivation and use of pedagogy. Therefore, in addition to seeking to identify the factors that motivate nursing faculty to use service learning, this study also tested the model of the theory of planned behavior using a path analysis to determine if the TPB and the external variables (type of curriculum, tenure status, and experience) predict the intention of nursing faculty to use service learning.

\section{Research Questions}

Four research questions that directed this study were based on the theoretical foundation for this study; the theory of planned behavior (Ajzen, 2004). 
Question 1: What is the relationship between behavioral beliefs and the intention of nursing faculty to use service learning?

Question 2: What is the relationship between normative beliefs and the intention of nursing faculty to use service learning?

Question 3: What is the relationship between control beliefs and the intention of nursing faculty to use service learning?

Question 4: Does the theory of planned behavior and the external variables (type of curriculum, teaching experience, tenure status) predict the intention of nursing faculty to use service learning?

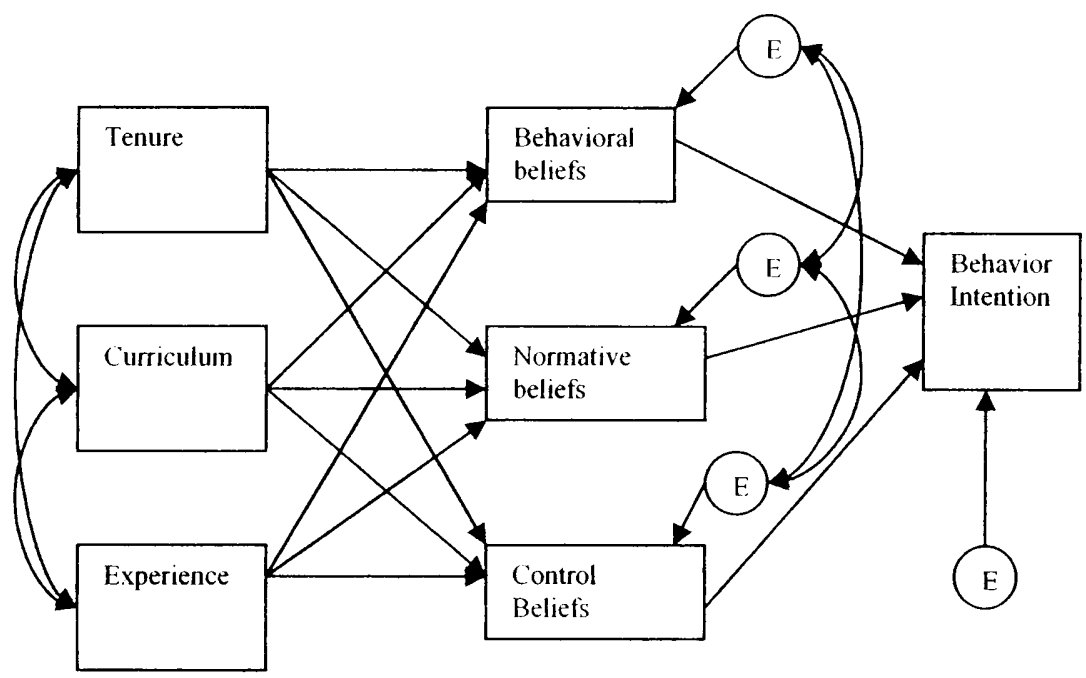

Figure 1. Conceptual model of proposed relationships among TPB constructs and external variables (tenure, curriculum, and experience).

The proposed path model shown in Figure 1 was created based on the conceptual model of the theory of planned behavior, as well as the predictor and criterion variables 
addressed in this study to indicate causal paths between variables. During path analysis, the model was used to represent the results of the statistical analysis.

\section{Significance}

This study had significance from several perspectives. From an educational and practical perspective, the significance lies in the identification and analysis of motivational factors that influence nursing faculty use of service learning. This information will assist administration and nursing faculty to design strategies to facilitate the implementation of a community based curriculum, which will also meet the $21^{\text {st }}$ century standards set forth by the AACN. It may also guide administration in the allocation of resources and institutional support services.

Further, there is limited research on the application of the theory of planned behavior to service learning. One study by Martin (1994) applied the theory of planned behavior to the use of service learning with higher education faculty from diverse disciplines that included nursing, but did not disaggregate that data by specialty area. This study applied the theory of planned behavior to the use of service learning with nursing faculty.

\section{Theoretical Framework}

The complexity of human behavior has been studied for decades. Many theories of motivation have emerged from areas of behavioral psychology, cognitive psychology, and social psychology that have attempted to describe and explain motivational factors in a variety of settings. However, the theory of planned behavior (TPB) has been adopted for this study for several reasons. The theory of planned behavior distinguishes between three types of beliefs (behavioral, normative, and control beliefs) to explain behaviors. In 
contrast, other theories integrate all the beliefs into a single measure. However, individual traits such as attitude have not been consistently predictive (Ajzen, 1991). The theory of planned behavior seeks to keep them as separate entities to measure, yet look at their interaction and influence upon each other. Each attribute is very different and plays an important role in behavioral outcomes (Ajzen, 1991).

The Theory of Planned Behavior for Motivation of Faculty

The theory of planned behavior is an extension of an earlier theory, the theory of reasoned action (TRA) developed by Ajzen and Fishbein (1980). The TRA originated in the late 1960's from the field of social psychology, and research that led to its creation focused on the relationship between attitudes and behavior. The TRA addresses behavior intention rather than attitudes as the main predictor of behaviors. It is believed that intention is the predictor of a behavior, and the theory can be utilized to "predict, explain, and influence human behavior in applied settings" (Ajzen \& Fishbein, 1980, p. ix).

Over the past several decades, the conceptual framework has been revised and updated by Ajzen leading to the current theory of planned behavior (TPB). The TPB has been used to predict and understand behaviors in a multitude of settings including healthcare, business, and education. In contrast to TRA, the TPB can be applied to situations where the individual may not be in full volitional control. This makes it applicable to a greater number of situations than the TRA.

There are two basic assumptions of the TPB. The first assumption is "people are rational and will make systematic use of information" (Ajzen \& Fishbein, 1980, p. 5), and the second major assumption is "human behavior is not controlled by unconscious motives or desires" (Ajzen \& Fishbein, 1980, p. 5). These assumptions will guide the 
understanding and application of this theory, and in doing so, present a behavior as something that is a reasoned versus an automatic response. Many studies have demonstrated that when decisions are being made, the beliefs of that individual influence those decisions, thus making the Ajzen model applicable to predict, understand, and eventually modify behaviors (Ajzen, 1991).

Ajzen (1991) stated that there are four measurable outcomes: (a) behavioral intention or motivation, (b) attitude towards the behavior, (c) social influences on that behavior, and (d) individual perceptions of the ability to control the behavior. The theory of planned behavior postulates that behavior is a function of salient beliefs in reference to a behavior (behavioral beliefs, normative beliefs, and control beliefs). According to Ajzen (1991) beliefs are formed about something by associating it with certain objects, characteristics, or events, thus linking that belief to a certain outcome, usually a positive or negative consequence. This forms an attitude toward that behavior. The schematic application of the TPB to this study is depicted in Figure 2.

Normative beliefs reflect the important referent individuals or groups who may approve or disapprove of a given behavior, while the control beliefs reflect the presence or absence of resources and opportunities. The more resources and opportunities faculty feel they have, the fewer obstacles they perceive; thus they can anticipate greater success and control over the behavior. Each of these outcomes can be applied to the use of service learning by nursing faculty. 


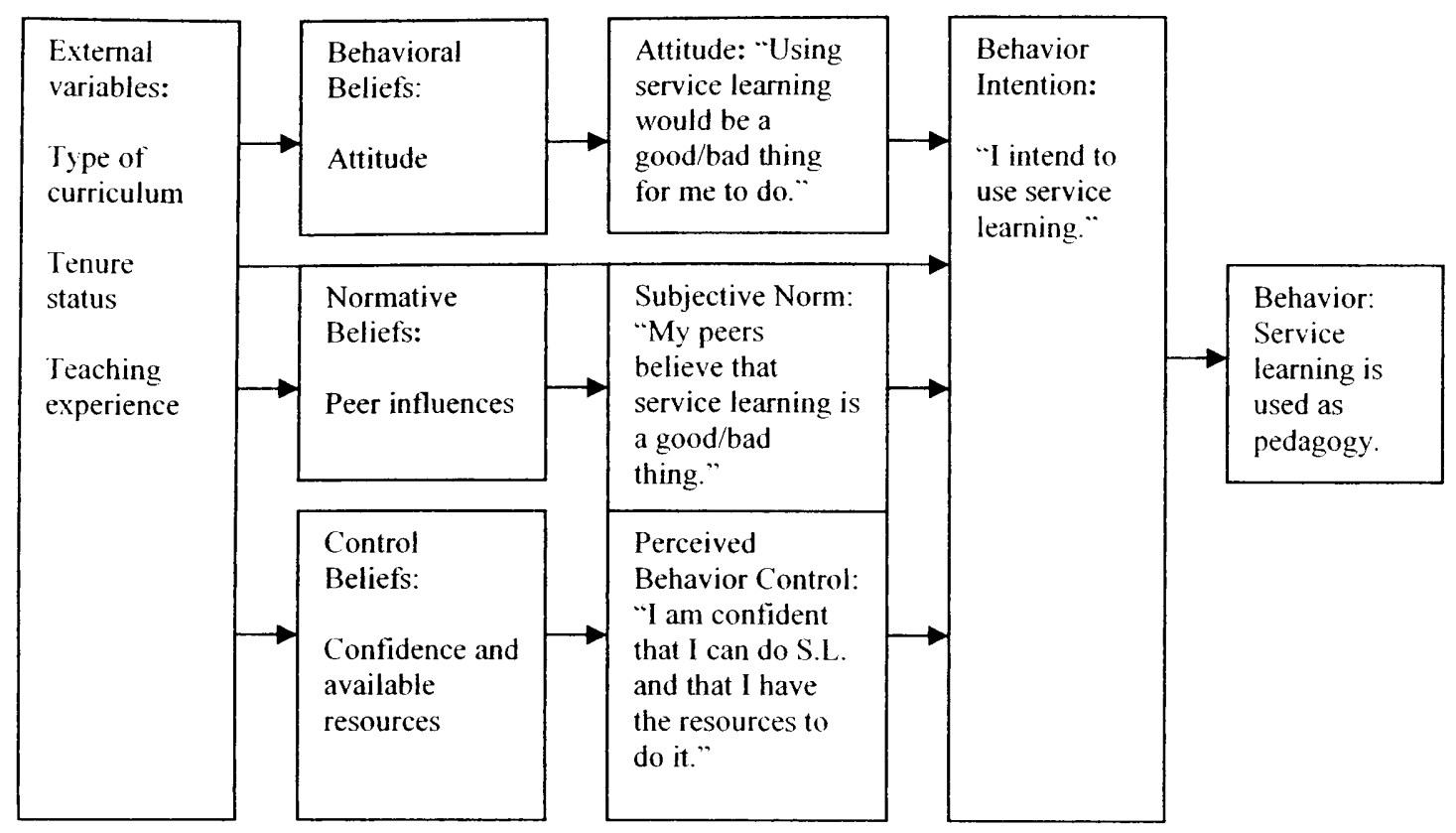

Figure 2. The theory of planned behavior applied to nurse faculty motivation to use service learning pedagogy

Intention. In the model, intention is the predictor of behavior. Ajzen (1991) explained intentions are assumed to capture the motivational factors that influence a behavior; they are indications of "how hard people are willing to try and how much of an effort they are planning to exert in order to perform the behavior" (p. 181). Intentions are influenced by personal and social functions: behavioral beliefs (attitudes) and normative beliefs (subjective norm). For nurse educators, intention may be measured by asking if the faculty member intends to use service learning in the coming school year or how many times he/she plans to use it as pedagogy.

Behavioral beliefs and attitudes antecedents. The first antecedent to intention in the TPB is an individual's personal influence or his/her attitude toward the behavior. Attitude is the product of behavioral beliefs. If a person believes that the outcome of 
performing a behavior will be positive, then he/she will have a positive attitude towards it (Ajzen \& Fishbein, 1980). Conversely, if the person believes that the outcome of a behavior will be negative, he/she will have a negative attitude toward it. For example, in nursing education, attitudes toward service learning could be considered interesting or boring, useful or useless, practical or impractical, or time saving or time consuming. Or as shown in Figure 2, an example for nurse educators is "Using service learning would be a good/bad thing for me to do."

Normative beliefs and subjective norm. The social influence on intention is termed the subjective norm, which is a product of the normative beliefs. If a person thinks that a specific group or individual will view the behavior as positive, then he/she will be more likely to perform the behavior (Ajzen \& Fishbein, 1980), and if he/she believes that a specific group or individual will view the behavior as something that is negative, he/she will be less likely to engage in that behavior. In nursing education, peer influences may arise from administration, faculty members, students, or individuals involved in tenure and promotion, or retention and dismissal committees.

Control beliefs and perceived behavioral control. Perceived behavioral control is the third antecedent to intention that has been added to the TRA model to make it the TPB model. It is the individual's perception of control in a situation, but also his/her perception of the ease or difficulty of performing the behavior, or his/her confidence in performing the behavior (Ajzen, 1991). Examples of this from nursing education may include curricular or professional regulatory constraints, individual experiences with service learning, financial concerns, or the belief that they have the academic freedom to include service learning in their courses. 
The TPB allows a researcher to study motivational traits both individually or in aggregate. Thus, when utilizing the theory to address a research question that seeks to explain, predict, and ultimately change behaviors, the researcher can look at individual influences so there is less blurring of influences, and changes can be seen more distinctly. Researchers can also view the aggregate, potentially leading to changes at an institutional or organizational level.

The TPB is applicable to a study of nursing faculty motivation to use the teaching pedagogy of service learning. If service learning has been demonstrated to be an effective methodology for enhancing student learning, and the nursing curriculum is congruent with service and community involvement, then it stands to reason that nursing faculty would be open to using the methodology in their classrooms. In contrast, if they are not using service learning pedagogy, the TPB may shed light on the factors that may deter them from using it and allow mechanisms to be put in to place to facilitate the use of service learning in nursing classrooms in the future.

\section{Definitions}

The concepts of service learning and community based curriculum have many definitions in the literature and therefore necessitate clarity for this study. The following is a description of the variations of definitions for these terms, as well as theoretical and operational definitions that have been chosen to provide a foundation for this study.

\section{Service Learning}

Service learning has been defined in a multitude of ways since its inception which may reflect the evolution of its application to various professions and settings. Most definitions of service learning include the same primary components: community service, 
academics, reflection, and civic responsibility. These commonalities thread through all definitions, with frequent references to John Dewey and constructivism as a theoretical foundation to the practice of service learning. Bringle and Hatcher (1999) defined service learning as a

course based, credit earning educational experience in which students participate in an organized service activity that meets identified community needs and reflect on the service activity in such a way as to gain further understanding of course content, a broader appreciation of the discipline, and an enhanced sense of civic responsibility (p. 179).

The Community Campus Partnerships for Health Organization (Seifer, 2006) is a non-profit organization that facilitates partnerships between health professionals in higher education and communities. They defined service learning as a

structured learning experience that combines community service with preparation and reflection. Students engaged in service learning provide community service in response to community identified concerns and learn about the context in which service is provided, the connection between their service and their academic coursework, and their roles as citizens (Community Campus Partnership for Health Organizations, 2006, ף2).

Theoretical definition. The definition of service learning for this study was determined by combining the definitions from the literature noted above, and responses from the group discussions held with a sample of the target population during the instrument construction for this study. Therefore, service learning was theoretically defined for this study as a structured learning experience characterized by all of the following: (a) learning objectives that meet the needs of the student, the community, and the profession of nursing, (b) structured time for student reflection on the experience from a personal, global, and professional perspective, and (c) enhancement of the student's sense of civic responsibility and professionalism in nursing. This definition 
emerged from group interviews that were conducted during the instrument construction and pilot test.

Operational definition. Service learning was operationally defined by the responses to items on the survey instrument developed to assess nursing faculty motivation to use service learning as pedagogy. The theoretical definition of service learning was provided on the instrument, and based on that definition, subjects were asked to use a 7 point rating scale to signify how likely it would be for them to use service learning in the current academic school year, and how many times they planned to use service learning in the current academic school year. The survey was derived from the Ajzen (1991) theory of planned behavior.

\section{Community Based Curriculum}

In the area of nursing education, there are several definitions of community based education and community based curricula. It has been defined as a philosophical perspective and/or as a setting. One definition that is cited by the American Association of Colleges of Nursing (AACN) is offered by Matteson (2000):

pedagogy that enables students to learn to provide nursing care for people no matter where they encounter them. It is a people based model of dialogue, collaboration, and mutual learning. Community based education is an expanded approach to nursing education. It offers the opportunity to use different teaching strategies and additional settings. However, the content taught includes health promotion and disease prevention as well as the nursing care of people of all ages as they encounter the need for medical or health care interventions (p. 5).

Hamner, Wilder, Avery, and Byrd (2002) described community based nursing as

a philosophy rather than a specific type of nursing. It includes care of the individual, 
family, and community wherever they are. It focuses on these parts and emphasizes partnerships with the community.

Theoretical definition. Community based curriculum was defined for this study as a type of nursing education curriculum characterized by all of the following: (a) students are prepared to practice nursing in a multitude of settings in the community, (b) there is a focus on partnerships with the community, and (c) the care of the individual, family, and community (wherever that may be) is incorporated into the coursework.

Operational definition. Nursing curriculum was evaluated by the responses to questions on the demographic portion of the survey that asked what type of curriculum was used in their respective Schools of Nursing (i.e., community based or non community based), utilizing the theoretical definition above.

In addition to definitions of service learning and community based curriculum, the theory of planned behavior includes several terms that must be defined theoretically and operationally for clarity of this study.

\section{Behavioral Beliefs}

Theoretical definition. Behavioral beliefs are defined as the individual's positive or negative evaluation towards performing a behavior (Ajzen \& Fishbein, 1980).

Operational definition. Behavioral beliefs were operationally defined by responses to relevant items on the survey instrument that asked the respondents to rate their attitudes towards the use service learning. Survey items that reflected this construct included questions that asked participants to rate service learning as boring or interesting, useful or useless, or complex or simple. 
Normative Beliefs

Theoretical definition. Normative beliefs were defined as the belief that a specific group or individual will view a behavior as a positive or negative act (Ajzen \& Fishbein, 1980).

Operational definition. Normative beliefs were operationally defined by responses to relevant items on the survey instrument that asked the respondents to rate the influence of other individuals such as administrators, students, or colleagues on their motivation to use service learning.

Control Beliefs

Theoretical definition. Control beliefs are the individual's perception of control in a situation, their perception of the ease or difficulty of performing a behavior, and their confidence in performing the behavior (Ajzen, 1991, p. 183).

Operational definition. Control beliefs were operationally defined by responses to relevant items on the survey instrument that asked the respondents to rate their ability to use service learning, whether they believe that they have resources available to use service learning, and if the university mission supports the use of service learning.

\section{Assumptions}

Several philosophical and structural assumptions underlie this study. Ajzen and Fishbein (1980) posed several assumptions when applying the theory of planned behavior.

1. "People are rational and will make systematic use of information" (p. 5).

2. “...[P]eople consider the implications of their actions before they decide to engage or not engage in a given behavior" (p. 5). 
3. "A person's beliefs represent the information (be it correct or incorrect) he has about his world, it follows that a person's behavior is ultimately determined by this information" (p. 79).

Assumptions have been made about the population that has been chosen for this study included:

1. The faculty who work in schools of nursing that are members of the American Association of Colleges of Nursing (AACN) will be influenced and guided by position statements from this organization.

2. The faculty who teach in schools that are accredited by the Commission on Collegiate Nursing Education (CCNE) or the National League for Nursing Accrediting Commission (NLNAC), as well as the Southern Association of Colleges and Schools (SACS) will strive to meet and maintain the highest professional standards and act as role models for schools that have not achieved those accreditations.

Assumptions about service learning as pedagogy included:

1. Service learning is an effective method of teaching.

2. Service learning has not been consistently applied to nursing courses.

Two assumptions about the nursing curriculum included:

1. The curriculum in nursing programs is tightly structured and partially scripted due to the mandatory regulations set forth by the national licensing exam that all nursing school graduates must pass in order to practice as a registered nurse in the United States. 
2. Nursing faculty have some control over decisions in how they teach in the curriculum.

\section{Overview of Chapters}

The current research on faculty motivation, the theory of planned behavior, service learning, and nursing education are discussed in chapter two. The method and procedures for this study are discussed in detail in chapter three, and a description of the methodological approach and design are provided, as well as a description of the instrument creation and the pilot study of the instrument. The data collection procedures and the protection of human subjects, data analysis, and the techniques for evaluation of the research findings are also detailed in chapter three. The interpretation, analysis, and evaluation of the research findings are in chapter four. In chapter five, the results are discussed in relation to the theory and the current literature on the topic. Implications for service learning pedagogy in schools of nursing are discussed. Recommendations for further research on service learning in nursing education are described. 


\section{CHAPTER II}

\section{REVIEW OF THE LITERATURE}

The research on the effects of service learning on student learning, community consciousness and moral and civic development has been articulated in the literature (Astin \& Sax, 1998; Driscoll, 2000). The implementation of service learning has also been widely researched and documented. However, a void appears in the research pertaining to faculty motivation to use service learning in higher education, satisfaction with student learning, and the rewards and barriers to the use of service learning, especially for nursing faculty.

Information on the needs of nursing faculty to implement service learning in their classrooms, as well as the reasons for the use of service learning is anecdotal at best. Examples arise from reports from nursing faculty who have used service-learning pedagogy in their classrooms who then describe their challenges and successes in the literature. Despite an exhaustive search in databases such as Elton B. Stephen Company (EBSCO) Academic Search Premier, Dissertation Abstracts, and the Cumulative Index to Nursing and Allied Health Literature (CINAHL), limited empirical research on nursing faculty use of service learning, particularly their motivation to use this pedagogy, was found.

The literature review was reported in four sections: (a) research on motivational factors that influence faculty use of new and innovative pedagogy, (b) research on faculty motivation to use service learning, (c) applications of the theory of planned behavior to research on faculty use of pedagogy, and (d) an analysis and critique of the research, and 
the potential contribution this study may make to the empirical research on service learning and the theory of planned behavior.

\section{Research on Faculty Motivation}

Four recent studies were related to faculty motivation and the influence of institutional support for faculty who use alternative pedagogy in higher education. Overall, the results indicated that the support of administration as well as a willingness to use different teaching approaches are important influences on faculty decisions to use creative pedagogy. Euster and Weinbach (1994) and Pribbenow (2002) investigated the influence of the complexity of the faculty role that has evolved over the past two decades on choices of pedagogy. Boyer (1990) discussed the gradual paradigm shift in higher education moving away from an emphasis on teaching and service, toward scholarship and publication. This concept has appeared in the literature from the perspective of faculty motivation to use new or creative pedagogy. The studies reviewed in this section are summarized in Table 1.

Euster and Weinbach (1994) examined the role of faculty rewards for community service activities. In this replication study of research conducted in 1981 and 1983, the researchers surveyed 115 deans, directors, and faculty in social work programs in the United States, with a response rate of $80 \%$. The statistical analysis entailed a comparison of $t$-tests between the earlier research and the current study. The researchers reported that $47 \%$ of the faculty stated that the most valued activity was publication, while in the earlier studies they had reported that teaching had been most valued. However, there was no change in the value placed on service over the span of 13 years. 


Author (Date) $\quad$ Focus $\quad$ Methodology

Dee, Henkin, \& Pell (2002) Teacher motivation and Survey; Statistical analysis ( $t$ institutional support for tests) innovative pedagogy

Euster \& Weinbach (1994) Faculty rewards for $\quad$ Survey of Deans and community service activities Directors of Social Work Perceptions of nursing program; $t$-tests

Hawks (1999) faculty on organizational Questionnaires; multiple culture and empowering regression analysis teaching strategies

Impact of innovative

Pribbenow (2002) pedagogy on faculty work Grounded Theory, Qualitative method (guided interviews; theme analysis

Pribbenow (2002) conducted a qualitative study exploring the impact of innovative pedagogy on faculty work. Using a grounded theory approach, the researcher interviewed 35 faculty members at one institution. Six major themes on the use of innovative pedagogy emerged: more meaningful engagement with teaching, a deeper connection with students, enhanced knowledge of student learning processes, increased 
use of constructivist pedagogy, improved communication, and a greater involvement with the community. Pribbenow (2002) also reported increased complexity of their faculty role and the need for an expanded view of opportunities for scholarly work.

Two studies (Dee, Henkin, \& Pell, 2002; Hawks, 1999) addressed institutional influences on pedagogical choices. Hawks (1999) studied the perceptions of nursing faculty concerning the organizational culture in their schools of nursing, what empowering teaching behaviors were used, and if a relationship existed between perceptions of organizational culture and use of empowering teaching strategies. A survey was created to measure faculty perception of the organizational culture, and selfreported use of empowering teaching behaviors defined as activities such as group analysis of problems, mentoring, and expanded role relationships. Five hundred sixtyeight questionnaires were mailed to faculty with a $49.5 \%$ response rate. Participants were primarily women with an average age of 48 years, not tenured, $\mathrm{PhD}$ level preparation, and an average of 16 years experience. Less than $50 \%$ of the faculty reported using empowering pedagogy. A multiple regression analysis indicated that the perception of the culture of the organization was not a statistically significant variable, yet their perceptions were moderately positive toward clients $(M=3.52, S D=.82)$, the impact of the mission $(M=3.43, S D=.59)$, and managerial maturity $(M=3.4, S D=.62)$. Hawks (1999) concluded that a client focused, stable organization with a strong mission was important to ensure the use of empowering pedagogy.

In 2002, Dee, Henkin, and Pell studied teacher motivation, commitment, and involvement in change related activities, by analyzing their perceptions of school support for innovation and creative functions. Surveys were sent to 517 full time teachers at large 
urban southeastern schools in the United States schools with predominantly African American and Hispanic populations. A total of $57.1 \%$ completed the Siegel Scale of Support for Innovation Instrument, an instrument with an internal consistency of .8694. Data analysis ( $t$-tests, correlation, and regression analyses) indicated that there was not a statistically significant difference by gender, but teachers who perceived support for innovation had clear responsibilities, good communication with colleagues, and were more willing to use innovative pedagogy, $R^{2}=.561, F(18)=73.93, p=<.01$.

These four studies emphasized the importance of institutional support for faculty who chose to use innovative pedagogy as well as the perception of faculty related to that support. Collectively, the researchers raised the issue of communication between faculty and administrators as well as the perspective of role expectations as concerns for pedagogical choices.

Faculty Motivation to Use Service Learning The use of service learning by faculty has been studied in prior research. However, Driscoll (2000) presented the research agenda for the next five years from Campus Compact which recommended further research to identify the motivational factors and the barriers to the use of service learning in higher education. Considering the important role that faculty hold in service learning, faculty members themselves need to be asked about their experience with the implementation of service learning in the classroom. Nine studies on faculty motivation to use service learning were reviewed in this section. Four of the studies addressed motivation of faculty to use service learning in a variety of disciplines (Abes, Jackson, \& Jones, 2002; Hammond, 1994; Hayden, 2004; Price, 2003) and are summarized in Table 2. Five additional studies (Bragg, 2000; 
Gelmon, Holland, Seifer, Shinnamon, \& Connors, 1998; Hinck \& Brandel1, 2000;

Robinson \& Barnett, 1996; Ward, 1998) addressed faculty use of service learning from an institutional perspective.

Table 2

Studies on Faculty Motivation to Use Service Learning

Author (Date) $\quad$ Focus $\quad$ Methodology

$\begin{array}{lll}\begin{array}{l}\text { Abes, Jackson, \& Jones } \\ \text { (2002) }\end{array} & \begin{array}{l}\text { Identification of factors that } \\ \text { facilitate and impede faculty }\end{array} & \text { Questionnaire } \\ & \text { use of service learning } & \\ & \text { Satisfaction with service } & \\ \text { Hammond (1994) } & \text { learning pedagogy } & \text { Survey } \\ & \text { Motivation to use service } & \text { Qualitative study } \\ \text { Hayden (2004) } & \text { learning } & \\ \text { Price (2003) } & \text { Use of service learning in a } & \text { Descriptive study } \\ & \text { Michigan institution } & \text { Cross tabs }\end{array}$

Abes, Jackson, and Jones (2002) studied factors that motivated and deterred faculty use of service learning. They designed a questionnaire to gather information from 43 institutions that were members of Campus Compact in Ohio. Surveys were sent to 
1343 faculty members, 252 who used service learning in their courses and 906 who did not use service learning. They received a $39 \%$ response rate from faculty in a variety of disciplines and types of programs, including social work, education, humanities, arts, physical and biological sciences, mathematics, engineering, computers, and the health sciences. In addition, qualitative data were obtained from several open-ended questions at the end of the survey. These questions focused on the relationship between teaching and scholarship pressures, the relationship with the community, institutional support, and other factors that may influence faculty.

An analysis of variance revealed a statistically significant difference between faculty who used service learning and those who did not use service learning, primarily in the areas of scholarship and research $(F=2.47, p=.014)$. Sixty percent reported that other faculty members were a major source of encouragement to use service learning, and $69.5 \%$ reported that student learning outcomes were a major motivating factor in using service learning. The statistically significant deterrents to using service learning were logistical problems with coordinating community experiences $(M=3.23)$ and the feeling that they did not know how to use service learning effectively $(M=3.18)$. Other deterrents were a lack of released time for course development. However, there were no statistically significant differences in motivation that related to institutional support or the consideration of tenure and promotion.

Hammond (1994) investigated faculty motivation to use service learning and satisfaction with service learning as pedagogy. Intrinsic factors that influenced the use of service learning were addressed, including autonomy, control of work, belief that their work has a purpose, and feedback from others. The instrument, created by the researcher, 
described three major components: the characteristics of service learning courses, the perceived support for service learning, and a faculty profile to describe the characteristics of faculty members who use service learning. The instrument was sent to 250 faculty members at 23 institutions who were currently using service learning, asking them specifically why they had made the decision to use service learning. The sample happened to include nine nursing faculty members. The return rate was $65.2 \%$.

Data analysis included frequency distributions, analysis of variance, chi square, and paired $t$ tests. The researcher reported that $32.2 \%$ of the respondents were full professors with $58.3 \%$ holding a doctoral degree in their specialty. Forty-one percent were tenured faculty, and $79.9 \%$ were over 40 years of age. An ANOVA yielded statistically significant findings for faculty motivation in curricular areas such as bringing relevance to course material $(M=1.31)$, encouraging self directed learning $(M=1.54)$, and improving student satisfaction $(M=1.61)$. The results indicated that outside factors such as service learning as a requirement in their workload $(M=3.19)$ and departmental influences $(M=2.94)$ were not statistically significant motivators for faculty use of service learning. Faculty tenure status did not yield statistically significant differences. However, only $20.2 \%$ indicated that involvement in service learning would be an asset when pursuing tenure status.

In the area of satisfaction, $94 \%$ agreed that they had the autonomy to choose to use service learning, while only $9.4 \%$ perceived curricular policies as an obstacle to using service learning. Ninety-two percent believed that the use of service learning helped meet community needs; however, only $45.7 \%$ believed that using service learning had helped them in the area of scholarship (presentations, publications, and research). Other results 
in the area of faculty satisfaction with service learning indicated that the use of service learning was strongly influenced by pedagogical motivation $(M=1.33)$, rather than personal reasons such as the influence of community service in their family life $(M=$ 2.36) and their own involvement in service in high school $(M=2.62)$.

The survey also included items related to faculty dissatisfaction with service learning. Seventy-one percent reported issues with coordination of the activities as a deterrent, and $65.8 \%$ reported time demands as a source of dissatisfaction. Ninety one percent reported that the use of service learning required more time and energy to accomplish than regular pedagogical choices, and $10.3 \%$ indicated inadequate compensation as a barrier to the use of service learning.

Price (2003) conducted a descriptive study of service learning at a college of agriculture and natural resources in Michigan. In addition to factors that motivated faculty to use service learning, factors that were important for integrating service learning into courses and the faculty's basic knowledge of service learning were studied. Two hundred seventy-two questionnaires were distributed to faculty members, with a response rate of $39.3 \%$. Statistical analysis consisted of means, frequencies, and cross tabulations. The findings indicated that the majority of faculty $(52.5 \%)$ had heard of service learning but were not using it. Factors with the highest mean ratings of items related to faculty use of service learning were personal interest $(M=4.32)$, needs of students $(M=3.83)$, and community interest $(M=3.65)$. Reported barriers to the use of service learning were preparation time $(M=3.64)$, lack of funding $(M=3.55)$, and faculty being unfamiliar with service learning $(M=3.42)$. 
In a qualitative, exploratory study that examined the motivation of college faculty use of service learning, Hayden (2004) interviewed faculty members from a variety of academic disciplines, including nursing, at six universities in South Florida. Seventeen faculty members were interviewed and eight faculty participated in a focus group discussion. Participants were asked general questions about why they used service learning, the benefits and deterrents to using service learning, and the type of support needed for them to continue to use service learning in their classrooms. Sessions were audio-recorded, transcribed, and analyzed for emerging themes. The results indicated that factors that influenced faculty use of service learning were primarily intrinsic and personal such as past experiences, valuing service and community involvement, relationships with peers, benefits to students and teaching, and lastly, the perceived career benefits.

Several studies were related to institutional support for service learning as shown in Table 3. Hinck and Brandell (2000) surveyed faculty and administrators in a random sample of institutions that were members of Campus Compact including public, private, and religious institutions. One hundred five surveys were mailed, with a return rate of $45 \%$. Ninety-nine percent of the respondents had an office specifically dedicated to coordination of service learning activities. However, when asked for their definition of service learning, responses varied greatly with no general consensus. An ANOVA was conducted indicating that the respondents who used service learning were more satisfied with the support that they receive than those who did not use service learning, $F(1,87)=$ $7.04, p=<.00$. In the area of faculty support for service learning, $80 \%$ of the faculty indicated that they believe that less than $10 \%$ of their peers used service learning. The 
respondents indicated that faculty did not value service learning $(M=4.4)$; however, the campus administration $(M=3.1)$ and the student body $(M=3.5)$ were perceived by the faculty to support service learning.

Table 3

Studies of Institutional Factors and Use of Service Learning

Author (date)

Focus

Methodology

Bragg (2000)

Faculty engagement in

Grounded theory

service learning

Gelmon, Holland, Seifer, Curriculum revision and Qualitative study

Shinnamon, \& Connors service learning

(1998)

Hinck \& Brandell (2000) Institutional support for Survey

service learning

ANOVA

Robinson \& Barnett (1996) Use of service learning in Descriptive study community colleges

Percentages

Ward (1998)

Institutional support for

Qualitative study

service learning

Gelmon, Holland, Seifer, Shinnamon, and Connors (1998) conducted a longitudinal multi-site study of the Health Profession Schools on Service to the Nation Program (a national demonstration program of service learning in health professions 
education programs) to evaluate and reform the curriculum taking into consideration the institutionalization of service learning in the curriculum. Researchers used a qualitative approach to gather data through focus group interviews, activity logs, and document analysis of reports from participating institutions. Three key factors emerged from the theme analysis. First, a balanced, stable, and reciprocal relationship needed to exist between the institution and the community organizations involved. Second, there needed to be active participation from all groups involved. Third, a thorough evaluation process needed to be completed.

Influences on use of service learning in higher education appear to be related to the institutional mission and administrative support. Several studies have examined the reciprocal relationship between the faculty and administration in the use of service learning. Faculty need the support of the administration and the administration believes that the success of service learning programs lies with the faculty. For example, Astin and Sax (1998) reported that while $80 \%$ of the faculty believed community service was important, there appeared to be a lack of awareness by faculty and a resistance to using service learning.

Ward (1998) conducted a study to evaluate the depth and breadth of institutional support for service learning at five institutions. Data collection included interviews with students, administration, and faculty in group and individual settings. Forty-three interviews were completed for the study. The major themes that emerged included the need for funding, strong administrative leadership, and faculty involvement. The role of administration was determined to be integral to the success of a service learning program. However, the faculty needed to be involved at all levels of the program. Faculty cited a 
lack of rewards or incentives and scholarship pressures as deterrents to the use of service learning.

Two recent studies considered faculty engagement in the decision to use service learning (Bragg, 2000; Robinson \& Barnett, 1996). Robinson and Barnett (1996) conducted a descriptive study of community colleges to determine the extent of academic involvement in service learning. They surveyed 773 institutions that included administration, faculty, and student services personnel. The results were reported in percentages. Thirty-one percent of the respondents offered service-learning courses, with $75 \%$ of those courses occurring since 1990 . Seventy-one percent of the faculty reported that five or fewer faculty taught the courses with service learning. Eighty-four percent of faculty were encouraged to participate in service learning through praise, recognition, and peer influence, yet less than $20 \%$ believed that it was a factor in tenure and promotion. The personnel with the primary responsibility in organizing service learning activities were faculty and student services in more than $50 \%$ of the schools. Faculty support was the highest rated factor in the success of a service learning program in this study. The highest rated barriers to the use of service learning were funding and release time.

Bragg (2000) used a grounded theory approach to study faculty engagement in service learning and the factors associated with their use of service learning. The researcher interviewed 12 faculty members from one liberal arts university. The data were coded and analyzed for patterns. The results suggested that all of the faculty were influenced by the institution to conduct service learning, and faculty stressed the importance of student learning rather than the type of pedagogy. Faculty members who had prior experience with service learning reported that they felt more comfortable with 
service learning and felt it aligned with their philosophy of education. Faculty who were more flexible, collaborative, and reflective reported to be more comfortable with using service learning.

Taken as a whole, these nine studies suggest that faculty engagement and the value that is placed on service learning is significant in promoting its use in higher education. In addition to faculty initiative to use service-learning, other factors are correlated with faculty use of this pedagogy, including institutional support in the areas of resources, recognition in workload, monetary rewards, and promotion and tenure consideration.

\section{Theory of Planned Behavior}

The theory of planned behavior (TPB) has been applied in education, business, and healthcare. In the field of nursing research, applications of the TPB have focused on the study of patient compliance and attitudes toward behaviors such as smoking (Harakeh, Scholte, Vermulst, de Vries, \& Engels, 2004) and sexual activity (Rye, Fisher, \& Fisher, 2001). In the area of education, TPB has been used to explain and predict student's behavior in areas such as studying and test taking (Beck \& Ajzen, 1991). It has also been used to examine faculty behaviors in a variety of situations, including interactions with students with disabilities (Conaster, Block, \& Lepore, 2000; Thousand \& Burchard, 1990). Several studies have been conducted that apply the TPB to study faculty motivation in various professions. Haney, Czerniak, \& Lumpe (1996) studied teacher motivation to implement science education reform, and Lumpe, Haney, \& Czerniak, (1998) applied it to a study on cooperative learning. The studies related to TPB and pedagogy are summarized in Table 4. 
Table 4

Studies Using the Theory of Planned Behavior (TPB) in Various Disciplines

Author (Date)

Focus

Methodology

Crawley (1990)

Intention to use investigative Survey Data

teaching methods

Correlation and regression

Conatser, Block, \& Lepore Attitudes of aquatic instructors Survey Data

toward of students with

disabilities

Haney, Czerniak, \& Lumpe Beliefs towards competency

based science model

Lumpe, Haney, \& Czerniak Intention to use cooperative

Martin (1994)

learning

Intention to use service

learning

Martin, Kulianna, Eklund, Intention to teach physical

\& Reed (2001)

education classes

Special education teachers

(1990)

attitude towards students with Correlation and regression

handicaps
Survey data

Correlation and stepwise

multiple regression analysis

Survey Data

ANOVA and regression

Survey Data

ANOVA and regression

Qualitative Study

Survey Data

Correlation and regression

analysis 
Conatser, Block, and Lepore (2000) examined the attitudes of aquatic instructors toward teaching students with disabilities using the TPB. After modifying an instrument from an earlier study based on the TPB, surveys were mailed to a sample of 82 instructors from 25 states, with a $48 \%$ return rate. Males and females were surveyed and the range of experience was from 2- 45 years, with more than $95 \%$ having prior experience working with disabled students.

A pilot study was conducted to determine the content validity of the instrument, with Cronbach alpha results of $.88-.91$. Correlations were calculated between students with mild to severe disabilities and teachers, indicating that the teachers' attitudes were more favorable toward students with mild disabilities, $M=3.33, S D=0.70$. Stepwise multiple regression analyses indicated that additional instruction in programs on how to teach students with disabilities, $R^{2}=.36, F(2,77)=4.22, p=.04$, and more certification in aquatics, $R^{2}=.27, F(1,78)=6.18, p=.02$, were best predictors of favorable attitudes toward students with disabilities. Other studies conducted using the TPB and intention to work with students with disabilities (Folsum-Meek \& Rizzo, 2002; Thousand \& Burchard, 1990) had similar results, with instructor confidence and attitudes toward disabled students demonstrating significance.

Martin, Kulinna, Eklund, and Reed (2001) studied the determinants of intention to teach physical education classes, including their own engagement in vigorous activity with students. One hundred eighty-seven physical education teachers from the Midwest were surveyed. No return rate was reported. The average age was 39.5 years, and the participants were $63 \%$ female. To determine the subjective norm, feedback was solicited from teachers and administrators. Cronbach alpha calculated for behavioral intention was 
.98 , behavioral control was .89 , subjective norm was .86 , and behavioral belief (attitude)

was .88. Data analysis consisted of correlations and multiple regression. The results indicated that attitude and subjective norm were predictive of the behavior of engaging in vigorous exercise during a physical education class, $R^{2}=.65, F(.04,10305)=56.39, p=$ .001 . The perceived behavioral control was also significant, $R^{2}=.61, F(.05,3312)=$ $160.96, p=.001$.

Another venue for the application of the TPB in education explored teachers' intentions to implement a specific pedagogical approach in the classroom. Haney, Czerniak, and Lumpe (1996) elicited teacher beliefs concerning their intention to implement four specific strands of a competency based science model (inquiry, knowledge, conditions, and applications). The instrument was constructed after conducting structured interviews of a sample of the target population to determine salient beliefs and referents. Construct validity was established by Cronbach alpha (attitude $=$ .75 , subjective norm $=.75$, and perceived behavior control $=.64$ ). Eight hundred surveys were distributed, with a return rate of $52.5 \%$. Regression analysis and an analysis of variance indicated that attitude and perceived behavioral control were statistically significant indicators of teacher intention to use four specific strands of science education model; inquiry, $R^{2}=.348, F(2)=32.070, p=.001$; knowledge, $R^{2}=.49, F(2)=14.244, p$ $=.001$; conditions, $R^{2}=.405, F(1)=20.386, p=.001 ;$ and applications, $R^{2}=.55, F(2)=$ $20.767, p=.001$.

Crawley (1990) explored the intentions of teachers to use investigative teaching methods. The instrument was created after soliciting salient beliefs and referents from the target population, hut no pilot test or Cronbach alpha levels were reported so it is difficult 
to assess construct validity. Fifty teachers from elementary and secondary physical science classes who were enrolled in a course that included concepts of investigative models of teaching were surveyed. Regression analysis and correlations indicated that attitude, subjective norm, and perceived behavioral control were related to the teachers' use of investigative teaching techniques at a statistically significant level, $R^{2}=0.60, F$ $(7,38)=41.36, p=0.0130$

Lumpe, Haney, and Czerniak (1998) studied the factors that influenced K-12 teacher intentions to use cooperative learning. In the application of the TPB, salient beliefs and referents were first identified by interviews with a sample of the target population. Alpha coefficients indicated that the constructs were adequate (attitude $=.97$, subjective norm $=.75$, perceived behavior control $=.61$, and intention $=.97$ ). The sample was from one state school directory. Two hundred twenty questionnaires were sent with a return rate of $53.5 \%$. Of the respondents, $72 \%$ were female. Regression analysis and analysis of variance indicated that the teachers' attitudes, subjective norm, and perceived behavioral control were related to intention to use cooperative learning at a statistically significant level, $R^{2}=.79, F(103)=55.6, p=.001$. The strongest predictors were control beliefs, $R^{2}=.19, F(105)=4.0, p=.05$, followed by behavior beliefs, $R^{2}=.51, F(105)=$ $36.6, p=.0000$.

Thousand and Burchard (1990) used the theory of reasoned action to determine teachers' attitudes and behaviors towards facilitating the social integration of students with handicaps into the classroom. They mailed fifty questionnaires to teachers in one state to elicit salient beliefs and referents towards providing social integration experiences for their students with handicaps. No Cronbach alpha coefficients were 
reported and thus it was difficult to assess construct validity. In addition to survey data, they collected performance data over an eight week period regarding social integration opportunities that participants arranged for their students. The response rate was $84 \%$. Correlation analyses indicated that attitude towards the behavior was significantly correlated to intention, $r=.53, p=.01$, and that the subjective norm was also significant, $r=.37, p=.01$. A multiple regression analysis revealed a weak relationship between intention and the actual behavior, $R^{2}=.22, p=.08$. However, a regression analysis of attitude, subjective norm, and intention showed a statistically significant relationship, $R^{2}$ $=.43, p=.05$. No $F$ statistics were reported. Further analysis of the data indicated that the external variable of level of education was found to be predictive of teacher behavior.

The previous four studies applied the TPB to a variety of pedagogical interventions (cooperative learning, competency based education, inclusive education, and investigative teaching techniques). The TPB allowed the researcher to consider multifactorial influences of motivation and successfully identified constructs that were predictive of teacher use of pedagogy.

The TPB has been used in one study on faculty perceptions toward service learning within a large public university (Martin, 1994). In this study, the theory of planned behavior was used as a theoretical foundation and qualitative data were collected utilizing an interview format. Martin (1994) asked participants to define service learning, the amount of time spent in service learning activities, their beliefs toward it, and what people approved or disapproved of their use of service learning. Fifteen graduate students were trained by the investigator to conduct the 15-20 minute interviews and 66 faculty members were surveyed in all academic programs at the institution, including nursing. 
The audio recorded interviews were transcribed and analyzed by the researcher using two independent raters for content analysis. The results indicated that $68 \%$ engaged in service learning, $33 \%$ devoted $10-20 \%$ of their time to service learning activities, faculty in nursing and other health sciences, and women going through promotion and tenure process reported more favorable attitudes toward using service learning.

Nursing Education

Although there has been little empirical research related to nursing faculty use of service learning, nursing has been included in larger studies on faculty use of service learning. For example, the American Association of Higher Education's multi year service-learning project by Astin and Sax (1998) included 18 disciplines including nursing, and Martin (1994) included nursing faculty in a study on use of service learning. However, no research was found specifically addressing nursing faculty and service learning to describe their beliefs about how it fits into the curriculum, or how it impacts upon their professorial position among fellow colleagues across campus in terms of promotion and tenure criteria.

Peterson and Schaffer (1999) examined the use of service learning as a strategy to develop group collaboration and research skills of student nurses. They surveyed students in a research course that used a service learning component. The instrument had both open and close-ended questions about their service learning activity. The results indicated the students felt that faculty needed to do more to facilitate the process and guide the experience. The researchers reiterated that educators must distinguish between service learning and a clinical practicum in the nursing curriculum. 


\section{Discussion}

\section{Critique of the Methods}

A total of 26 studies were included in this literature review. There were four qualitative studies (Bragg, 2000; Hayden, 2004; Pribbenow, 2002; Ward, 1998), fifteen quantitative studies, and seven used the procedures associated with the theory of planned behavior.

Overall, the quantitative studies had adequate sample sizes, response rates, and statistical applications. The quantitative studies had a wide range of participants, from 50 subjects to 906 subjects. However, the results of several of the quantitative studies have limited generalization because the studies were conducted at a single institution (Haney \& McArthur, 2002; Martin, 1994; Peterson \& Schaffer, 1999; Price, 2003). The response rates ranged from $39 \%$ to $84 \%$, with the median response rate between $45 \%$ and $65 \%$, which is acceptable for mailed survey studies. The inferential statistics applied most frequently were $t$-tests, analysis of variance, correlation, and regression. Researchers who used a qualitative method included between 12 and 43 participants, with individual interviews and group interviews both incorporated in that number.

\section{External Variables}

A major concern in the field of service learning is the lack of consensus on the definition of service learning. Many researchers did not include a definition of terms, which raises the question of consistency. Only two studies (Hinck \& Brandell, 2000; Peterson \& Schaffer, 1999) addressed this issue. Hinck and Brandell (2000) asked the respondents to provide a definition in the questionnaire, but they reported that there was 
no general consensus among the respondents concerning how service learning was defined. In the nursing literature, the attempt to study service learning becomes even more complicated with the confounding issue of clinical experiences in nursing. Peterson and Schaffer (1999) defined service learning for their study through a focus group interview of nurse educators prior to the development of their survey instrument, thereby providing a consistent foundation for the study.

In many circumstances, the type of curriculum can drive the use of pedagogy. The curricular influence on the use of service learning has not been fully explored in the research, only four researchers addressed curriculum (Ben-Zur, Yagil, \& Spitzer, 1999; Gelmon et al., 1998; Martin, 1994; Robinson \& Barnett, 1996). These researchers did so from two perspectives by asking; what effect did service learning have on the curriculum, or which type of curriculum lends itself to service learning?

Gelmon et al. (1998) studied program revision to include service learning, and in doing so addressed faculty beliefs about service learning. They concluded that a key factor in curricular reform to include service learning is faculty involvement. In a second study, Ben-Zur et al. (1999) reported that nursing curriculum changes needed to occur to assist student transition into the projected future healthcare system. However, students were surveyed for this study, not faculty.

Two researchers examined curricular influences from the perspective of which type of curriculum best lends itself to service learning. Martin (1994) stated that service related programs were more likely to use service learning, and a study by Robinson and Barnett (1996) reported that social sciences and humanities were more likely to use service learning in their curriculum. 
Most researchers gathered demographic data from the respondents including tenure status, educational preparation, and teaching experience, yet only three researchers included these variables in their results. Martin (1994) reported that faculty who were in the tenure and promotion process were more likely to use service learning. In contrast, two other researcher teams determined that tenure and promotion issues did not have an impact on faculty decisions to use service learning (Abes et al., 2002; Robinson \& Barnett, 1996).

\section{Application of Theory}

Many studies on faculty motivation did not have a specific theoretical foundation. However, all of them examined at least one construct that is found in the theory of planned behavior (TPB), either individually or in conjunction with other traits of motivation. The TPB allows for consideration of personal attitude (behavioral beliefs) and social influences (subjective norm), as well as takes into account influences that are not under the control of the individual such as financial constraints and institutional limitations (control beliefs).

Researchers identified the importance of attitude toward service learning and the role of attitude in the actual use of service learning as pedagogy (Bragg, 2000; Hammond, 1994; Hayden, 2004; Hinck \& Brandell, 2000; Holland, 1999; Price, 2003). Several researchers discussed the major role that peer pressure played on faculty use of service learning (Abes, Jackson, \& Jones, 2002; Crawley, 1990; Dee, Henkin, \& Pell, 2002; Hayden, 2004; Thousand \& Burchard, 1990). Other researchers examined the influence of confidence and resources on the motivation to use service learning (Abes, Jackson, \& Jones, 2002; Bragg, 2000; Bringle \& Hatcher, 2000; Hayden, 2004; Price, 
2003; Robinson \& Barnett, 1996; Ward, 1998). The results of these studies identified a variety of motivational factors that influenced the faculty. It appeared that motivational factors, although obviously an individual predictor, may also be different based on the academic content and curriculum, which may vary between disciplines. Also, faculty confirmed the importance of using innovative pedagogy. However, the research does not fully support or explain the reasons why the faculty does not use it.

Many researchers examined the effects of attitude (Bragg, 2000; Hammond, 1994; Hayden, 2004; Hink \& Brandell, 2000; Holland, 1999; and Price, 2003), peer pressure (Abes, Jackson, \& Jones, 2002; Crawley, 1990; Dee, Henkin, \& Pell, 2002; Hayden, 2004; Thousand \& Burchard, 1990), and control issues such as resources and confidence (Abes, Jackson, \& Jones, 2002; Bragg, 2000; Bringle \& Hatcher, 2000; Hayden, 2004; Price, 2003; Robinson \& Barnett, 1996; Ward, 1998), yet it was unclear how each construct was defined and measured. In contrast, the researchers who applied the TPB clearly defined each construct and developed guidelines for measurement of those constructs.

However, several researchers (Martin, 1994; Thousand \& Burchard, 1990) failed to follow the guidelines set forth by the theorist when applying the TPB to the study of faculty motivation issues. Ajzen (2004) stated that a group interview of the target population must be conducted to identify the salient beliefs and referents; choosing items from the literature will not suffice. In addition, a pilot test must be conducted and coefficient alphas calculated to validate the internal consistency of the constructs being measured. This study followed the recommendations from the theorist to apply the TPB 
by providing clear definitions for service learning, community based curriculum, and each construct of the TPB.

The theory of planned behavior has been used to investigate faculty motivational issues in specific school subjects such as special education and physical education (Conaster, et al., 2000; Martin, et al., 2001; Thousand \& Burchard, 1990), as well as the motivational factors faculty face when teaching with new pedagogy (Crawley, 1990; Haney, et al., 2001; Lumpe, et al., 1998). The results of the literature review indicated that the theoretical application of TPB to nursing education is an area that needs further research. Nursing was included in the study by Martin (2001), but the results were not reported by specific discipline. The TPB has been used in a variety of educational specialties, but it has not been used in nursing which is unique to other disciplines such as mathematics and science, that do not have practical experiences.

The relationship between the faculty, administration, and the students appeared to be an integral part of successful service learning programs at an institution. However, the research has gaps concerning the use of service learning by educators in nursing education. The research from the nursing literature by Hawks (1999) and Schaefer and Zygmont (2003) indicated that the nursing faculty did not use innovative pedagogy, yet the perception of their teaching style was student centered. These studies were conducted within the past five years, indicating that nursing faculty may not be moving toward the $21^{\text {st }}$ century standards set by the AACN.

The present study was designed to add to the body of knowledge concerning pedagogical approaches to nursing education. Applying TPB to a study of nursing faculty can bring a new perspective to the role of service learning in programs that require 
clinical experiences outside the classroom, as well as a licensing exam. Finally, research to discover a clearer set of relationships between teaching experience, tenure status, curriculum, and TPB to the use of service learning will add to the body of research on faculty motivation and use of pedagogy.

\section{Summary of Chapter Two}

The literature review revealed studies that examined the motivational factors for faculty use of new and innovative pedagogy as well as the use of the specific pedagogy of service learning. The application of the theory of planned behavior to faculty motivation was described, including one study on the use of TPB with service learning. The external variables (tenure status, teaching experience, and curriculum) were identified during the review of the literature as well as specific definitions for service learning and community based curriculum. 


\section{CHAPTER III}

\section{METHOD}

The purpose of this study was to answer the question, "What are the factors that influence the use of service learning by nursing faculty?" There were three research questions that, when addressed, provided insight to the factors. A second objective of this study was to determine whether the TPB as a model, fit nursing education and motivation to use service learning. The fourth research question addressed this perspective of the study.

1. What is the relationship between behavioral beliefs and the intention of nursing faculty to use service learning?

2. What is the relationship between normative beliefs and the intention of nursing faculty to use service learning?

3. What is the relationship between control beliefs and the intention of nursing faculty to use service learning?

4. Does the theory of planned behavior and the external variables (type of curriculum, teaching experience, and tenure status) predict the intention of nursing faculty to use service learning?

The predictor variables were the constructs from the TPB, behavioral beliefs (attitude), normative beliefs (peer influences), and control beliefs (confidence and resources), as well as external variables extracted from the literature review. These included the type of nursing curriculum (community based or non-community based), teaching experience, and tenure status. The criterion variable was the intention to use service learning. 


\section{Research Design}

The study employed a correlational, predictive design to answer the research questions. This design was selected based on the research questions posed, as well as the theoretical foundation of the study (the theory of planned behavior). In TPB, Ajzen (1991) postulated that human behavior is guided by three kinds of beliefs (behavioral, normative, and control beliefs), which all influence intention. Intention captures the motivational factors that influence the final behavior. Because the researcher attempted to discover the relationship among the variables, a correlational design was appropriate.

A path analysis was conducted to determine whether the TPB, as a model, fit nursing education and motivation to use service learning. Path analysis has been applied to other studies that used the theory of planned behavior. Research by Crawley and Koballa (1992) studied motivational factors that influence Hispanic American student attitudes towards high school chemistry, and Davis, Ajzen, Saunders, and Williams (2002) used path analysis in a study of the factors that influence African Americans to complete high school. An e-mail from Icek Ajzen (2004), one of the original creators of the theory of planned behavior, stated that the use of path analysis with the theory was "superior to regressions in that they permit an overall test of model fit."

Three basic conditions needed to exist for path analysis to provide meaningful results: (a) the variables must be well measured, (b) important causal variables cannot be left out of the model, and (c) the sample size must be adequate (Gall, Gall, \& Borg, 2003). These conditions were addressed in this study by (a) performing group interviews of individuals from the target population for construct development and conducting a pilot study on the instrument prior to its distribution to the respondents, (b) through a 
thorough literature review to identify external variables (i.e., type of curriculum, tenure status, and teaching experience), and (c) by ensuring an appropriate sample size by conducting a power analysis, and ensuring an adequate response rate by prompting respondents with reminders and phone calls.

\section{Sample and Setting}

The sample was comprised of nursing faculty who taught in baccalaureate programs accredited by the Southern Association of Colleges and Schools (SACS) and members of the American Association of Colleges of Nursing (AACN), and those schools that have accreditation by either the Commission on Collegiate Nursing Education (CCNE) or the National League for Nursing Accrediting Commission (NLNAC). SACS is an accrediting organization for a variety of higher education institutions in the southern United States. AACN is the national voice for baccalaureate programs and works to establish quality standards for programs through education, research, advocacy, and publications. The AACN has recommended a shift in nursing education away from a hospital based curriculum and more toward a community based curriculum. Finally, CCNE and NLNAC are the accrediting bodies for nursing programs in the United States. Thus, the sample represented faculty from nursing programs in the Southeastern United States that were members of AACN and were accredited at a professional level as well as at a higher education level.

To determine an appropriate pool from which a sample would be drawn, the 11 SACS states were listed. Next, all the baccalaureate nursing programs in those states were listed and compared to the membership list for AACN. Those who were not members of AACN were eliminated. The list was then compared to the schools 
accredited by the CCNE and NLNAC, the two major accrediting agencies for nursing programs. Those baccalaureate programs that were not accredited by either body were eliminated from the list. The remaining list consisted of 156 schools of nursing that met the criteria for this study.

Both CCNE and NLNAC schools were included since both are recognized accrediting bodies for nursing programs. The inclusion of schools accredited by either group increases the credibility of the study and attempts to establish the influence of a community based curriculum on choices of pedagogy.

The sample was chosen as a representative sample of the population of nursing faculty members who teach in baccalaureate programs in the Southeastern United States. To determine the minimum sample size, a power analysis for multiple regression was conducted using Power Analysis and Sample Size (PASS, 2002). The results indicated that a sample size of 150 subjects achieved $80 \%$ power to detect $R$-squared of $10 \%$ attributed to six independent variables (behavioral beliefs, normative beliefs, control beliefs, type of curriculum, tenure status, and experience) using an $F$-Test with a significance level (alpha) of 0.05 .

Three hundred thirty subjects were surveyed to achieve a minimum sample size of 150. Random stratified sampling was conducted in the following manner. All the eligible schools were assigned a number, and a random number table was used to select the school sample. A total of 30 schools were chosen, estimating that there was an average of 10 full time faculty in each program. Of those 30 schools, two were removed from the randomly chosen sample (University of Southern Alabama and Southern University and A \& M College) due to a catastrophic hurricane that hit the gulf coast in September, 
2005 , and replaced with two other randomly selected schools from the list. Surveys were mailed two weeks later than planned to allow surrounding schools to recover from the storm. Table 5 lists the schools that were surveyed and the type of curriculum that respondents reported they used.

Table 5

Type of Curriculum for Participating Universities
Community - based
Hospital - based
Both

$\begin{array}{lll}\text { Auburn University } & \text { Brenau University } & \text { Georgia State University } \\ \text { Florida Atlantic University } & \text { Jacksonville University } & \text { Louisiana College } \\ \text { Murray State University } & \text { Lamar University } & \begin{array}{l}\text { Medical University of South } \\ \text { Carolina }\end{array} \\ \text { Radford University } & \begin{array}{l}\text { University of North Carolina } \\ \text { (Wilmington) }\end{array} & \text { Mary Mount University } \\ \text { University of West Florida } & \text { Lamar University } & \text { Middle Tennessee University } \\ & & \begin{array}{l}\text { Shenandoah University } \\ \end{array} \\ & & \begin{array}{l}\text { University of Alabama } \\ \text { (Birmingham) }\end{array} \\ & \text { University of South Carolina } \\ & & \text { University of Texas at Tyler } \\ & & \text { Valdosta State University }\end{array}$




\section{Instrument Development}

The instrument was developed in accordance with the guidelines described by Ajzen and Fishbein (1980). First, group interviews with representatives of the target population were conducted to determine salient beliefs and referents. Then a pilot study was conducted to validate the instrument constructs. These procedures allowed the researcher to identify the salient beliefs and referents about each construct, using the responses from nursing faculty as a basis for the formulation of the items contained in the survey. Ajzen (1991) stated that several arbitrary questions from other similar studies will not suffice since this produces measures with low reliability. He also stated specific, appropriate items will arise from formative investigation of the specific population and settings, thus the recommendation for group interview and pilot test prior to distribution of the survey.

The results from the group interview were used to identify behavioral, normative, and control beliefs, and subsequently created the items for the instrument. Beliefs are considered very important in the TPB. The belief strengths of an individual play a large role in guiding a person's decision to perform a behavior. Ajzen (1991) stated that the variables in the TPB (behavioral beliefs, normative beliefs, and control beliefs) cannot be observed directly, but they must be inferred from responses that come from the questionnaire.

Procedure for Determining Beliefs

Two group interviews were conducted during the months of March and April of 2005 , each lasting approximately one hour. The group interviews consisted of 7-8 faculty members from two South Florida nursing programs that met the previously mentioned 
association affiliations; one used a community based curriculum while the other had a hospital based program. The faculty members were contacted via telephone or electronic mail to describe the purpose of the study and the contribution that the interview would play in the creation of the instrument. Their willingness to participate was solicited and confirmed, and the logistical arrangements for the meeting were made. For their convenience, the sessions were held at the institutions of the participants.

The interviews began with an introduction of the researcher, a review of the purpose of the group meeting, the general format for the discussion, and the potential benefits of their responses. The participants were assured their anonymity would be protected. Each participant was given two copies of the group interview consent form (Appendix A). After reading the letter, they were asked to sign one copy and return that to the researcher, then keep the second one for their records. They were told that the sessions would be audio-recorded and if they had any concerns related to this, they were given the opportunity to remove themselves from the discussion at any time. The audiorecorder was turned on, and a verbal confirmation of the participants' understanding of the consent and process of the interview was obtained. The participants were given a number to identify themselves prior to speaking to allow for anonymity as well as to allow the researcher to determine if there was participation by all of the participants, or if the discussion was from a select few.

Because there was no distinct definition of service learning in the literature or specifically for nursing, the discussion began with clarification of a working definition of service learning. Participants reviewed a definition of service learning that was derived from the literature, and then were asked to define service learning in nursing education. 
Their input helped create the final definition used in this survey. The following questions were asked to assist in the formulation of a definition of service learning: (a) How do you define service learning? (b) Can you give an example of service learning? (c) How is service learning different from clinical nursing experiences? (d) How would you change the following definition of service learning to fit nursing education? Service learning is a structured learning experience characterized by all of the following: (a) learning objectives that meet the needs of the student as well as the community, (b) structured time for student reflection on the experience from a personal and global perspective, and (c) enhancement of the student's sense of civic responsibility.

Following the discussion on service learning traits, the questions moved to elicit behavioral beliefs. The following questions were asked: (a) What do you see as the advantages of using service learning in your classes during the coming school year? (b) What do you see as the disadvantages of using service learning in your classes during the coming school year? (c) Is there anything else you associate with using service learning in your classes during the coming school year?

To determine normative beliefs, the following questions were asked: (a) Are there any individuals or groups of people who would approve of your using service learning in the coming school year? (b) Are there any individuals or groups of people who would disapprove of your using service learning in the coming school year? (c) Are there any individuals or groups of people who come to mind when you think of using service learning?

To generate a list of the control beliefs, the following questions were asked: (a) What factors or circumstances would enable you to use service learning in the coming 
school year? (b) What factors or circumstances would make it difficult or impossible for you to use service learning in the coming school year? (c) Are there any other issues that come to mind when you think about the difficulty of using service learning in the coming school year?

After lengthy discussion on the above topics, participants were asked if they had any further comments, questions, or clarifications of anything that was discussed during the session. In closing the discussion, participants were reminded that the researcher's contact information was on the consent letter, and if they had any questions, concerns, or comments they could contact the researcher or the committee chair at any time. They were told that in the coming weeks, they would be receiving a copy of the final instrument to complete. They were asked to complete and return the instrument for the pilot study to confirm that the information was clear and accurate. They were thanked for their time, and acknowledged with a thank you note that included a 10 dollar gift certificate for Blockbuster Video.

Instrument Development

The audio-taped discussions were transcribed verbatim and analyzed by the researcher. The definition of service learning was adapted to this study population, and the salient beliefs and referents were determined for this study population. Following the recommendations of Ajzen and Fishbein (1980), the researcher chose the top 75\% of all of the salient beliefs and referents identified by the group participants. Using the instrument template provided by Ajzen (2005), a modified instrument was created and resulted in a self-report survey. 
Each construct of the model was measured on a 7 point scale. There were 14 items that measured behavioral beliefs (attitude), 16 items that measured normative beliefs (peer influence), 16 items measured control beliefs (confidence and resources), and 3 items measured intention (motivation). To determine the use of a community based curriculum, the definition chosen for this study was provided and the respondents were asked (based on that definition), if they taught in a community based curriculum (yes/no). To determine tenure status the participants were given a choice of tenure or not tenured, and to determine their teaching experience they were asked to write in the number of years that they had been teaching nursing.

The behavioral beliefs, or attitude towards using service learning were measured using a 7 point scale using adjective pairs such as: interesting - boring, affordable costly, useful - useless, appropriate - inappropriate, time saving - time consuming, creative - unimaginative, successful - unsuccessful, practical - impractical, active passive, simple - complex.

The normative beliefs, or the influence of peers or how people important to them feel about using service learning, were measured using a 7 point scale using items such as: My.... administrators, colleagues, students, etc, think I should/should not use service learning". Their motivation to comply with peers was measured with the item: "Generally, I comply with my...administrator, colleagues, and student wishes".

Lastly, the perceived behavioral control component derived from the theory of planned behavior was measured using similar scaling structures. Again, specific components of the questions were determined by the interviews and included measurements of the degree that the respondents have the opportunity, confidence, 
ability, and resources to use service learning. Examples of items include, "I have the knowledge to use service learning", "If I wanted to, I could use service learning", and "There is adequate funding support for me to use service learning".

The criterion variable in this study was the intention to use service learning. The definition of service learning was stated on the instrument (which was taken from the responses from the group interview) assuring that the definition had been adapted to nursing faculty. The participants were asked several questions on their intention to use service learning in the coming school year. It was measured on a 7-point scale (likely to unlikely) as well as by asking the respondent to indicate the actual number of times that they intended to use service learning in the coming school year.

\section{Pilot Study}

To establish the content validity of the measures for behavioral beliefs, normative beliefs, and control beliefs, the researcher conducted a pilot test of the modified survey with the group interview participants and a sample of individuals who mirrored the target population. The survey, with a cover letter (Appendix B), was mailed to the group interview participants.

According to Ajzen (2004), content validity is established through the group interview portion of the instrument design because the items emerged from the faculty's own beliefs, obtained through the face-to-face discussions.

\section{Reliability}

The reliability of the instrument for this study was confirmed in several ways. The entire instrument was developed in accordance with the theoretical guidelines from the theory of planned hehavior. The survey template provided by Ajzen (2004) was modified 
based on the salient beliefs and referents derived from group discussions with a sample of nurse educators. A pilot test was conducted, and Cronbach alpha for reliability were calculated. Cronbach alpha, also called the alpha coefficient, is a statistical measure of the degree to which the items consistently measure the same construct. This tests the internal consistency. Gall, Gall, and Borg (2003) state, "An alpha of .52 is low, but sufficient for instruments used in exploratory research" (p. 261).

The acceptable alpha coefficient for this study was set at .75 , which correlates closely with the current research using the theory of planned behavior in education (Conaster et al., 2000; Lumpe et al., 1998). Previous researchers using the TPB have reported Cronbach alpha results for consistency of each construct including intention, attitude, subjective norm, and perceived behavior control. For example, Haney, Czerniac, and Lumpe (1996) conducted a study on teacher's intentions to implement a competency based model for teaching science. They achieved alpha coefficients of .75 for attitude, .75 for subjective norm, and .67 for perceived behavior control. Then Lumpe et al. (1998) studied teacher's intention to use the pedagogy of cooperative learning. They obtained alpha coefficients of .97 for intention, .82 for attitude, and .61 for perceived behavior control. Conaster, Block, and Lepore (2000) reported alpha coefficients between .89 and .91 for intention, attitude, subjective norm, and perceived behavior control. These alpha coefficients were used as a guide to determine the consistency of the instrument for this study.

Alpha coefficients for this study were .97 for intention, .90 for behavioral beliefs, .91 for normative beliefs, and .87 for normative belief items. Initially, the alpha coefficient for perceived behavior control was .75. However, upon review of the survey 
items for this construct, the scale had been reversed for one item. When that item was recoded, the alpha coefficient increased to .87 , and the corrected scale for that item was included in the final survey. Other minor modifications were made for the final survey which included adjustments in the level of education item for clarity, as well as cosmetic changes.

Procedure for Protection of Human Subjects

Permission and approval for data collection was obtained from the Florida International University Institutional Review Board (IRB). The IRB submission contained a written description of the methodology, the benefits of the proposed research, and the provisions taken to protect the anonymity and confidentiality of the study participants. For group discussion participants, letters of informed consent and assent may be found in Appendix A. The cover letters for the pilot study (Appendix B) and the survey cover letter (Appendix C) are also provided.

\section{Data Collection}

Once the final instrument was created and the institutions were identified for the study, the dean or department chair of those schools were contacted. The study was described to him/her, and the names of the full time undergraduate faculty members were solicited. Some schools provided actual names of faculty members, while many of them referred to their website for a list of their faculty. Survey packets were then mailed directly to each faculty member. In addition to a cover letter (Appendix C) and a self addressed stamped envelope, the packet included a demographic data sheet and definitions of service learning and community based curriculum as well as the survey (Appendix D). 
Facilitating an adequate response rate. Given that the best way to avoid a low response rate in a study is to prevent it from occurring (Dey, 1997), tactics such as the pilot study as well as follow-up e-mail messages and telephone calls were completed to facilitate the highest response rate possible. Ten to 14 days after the initial mailing, a reminder e-mail (Appendix E) was sent to the participants, emphasizing the importance of his/her input. When the response rate was still not satisfactory, a second e-mail was sent to emphasize the importance of his/her response. Finally, phone calls were made to participants from five schools with less than $50 \%$ respondents in an attempt to improve the response rate.

The non-respondents were compared to the respondents in relation to the type of institution and curriculum to determine if there were any major demographic variables that accounted for the non-respondents. Also, the surveys returned after the reminders were sent were analyzed to determine the direction and amount of bias from the original respondents. Sixty-seven percent of the respondents returned the survey after the initial mailing. The rest of the surveys were returned after the reminder. The phone calls to the schools with less than $50 \%$ response rate did not yield any further responses.

There were no obvious differences in the response rate related to the type of curriculum used by the institution. However, it appeared that the differentiation between the responders and non-responders could be attributed to storms that occurred during the data collection period. Three hurricanes occurred during September and October 2005. Hurricane Katrina struck August 29, 2005 and delayed the initial mailing of the surveys for two weeks. As noted previously, two schools located in Baton Rouge, Louisiana, and 
Mobile, Alabama were closed after Hurricane Katrina and were not receiving mail, so they were eliminated from the random sample.

The second storm named Hurricane Rita struck Texas and Louisiana on September 24, 2005, eight days after the initial mailing occurred. Twenty-five surveys were sent to a school in Texas which was closed for three weeks after Hurricane Rita. Of the 25 surveys mailed to that school, six were returned prior to the hurricane, and none were returned after the hurricane. Attempts to contact them after the storm resulted in notices on the internet that the school was closed. The third storm, Hurricane Wilma, struck the southern peninsula of Florida October 24, 2005, closing many schools for 1014 days. Only two surveys were received after that storm, and they were from schools in Georgia. Sending e-mail reminders to schools was compromised due to hurricane related power outages.

\section{Procedure for Survey Data Analysis}

Once the surveys were returned, one question on the final survey was omitted entirely because of confusing wording. That item was an open ended question, 'How many times do you plan to use service learning in the current academic year?' Responses to that question included a single number or a range of numbers, the number of clinical hours in the course, or the number of students. Other respondents used word answers such as 'several', 'many times', 'during post conference', 'everyday', or there were comments written in the space such as 'question too broad' or 'difficult question'.

An item on the pilot survey that inquired about the participants' educational background had appeared to confuse the pilot respondents. A list of degrees in nursing and education on the scale was provided, with a space for "other". Many of the pilot 
respondents checked more than one degree, or wrote messages on the survey indicating that the item was confusing. Therefore, for the final survey the item was changed to indicate the highest level of education specifically for nursing. A second question asked if the respondent had a degree in any other field, and allowed them a space to write in any other degrees they may have earned. This appeared to resolve any confusion concerning the question about their level of education.

Data analysis was conducted using demographic data as well as scored responses to the scaled instrument items. The results are reported with frequency data, correlation analysis, and path analysis.

\section{Demographic Data Analysis}

The demographic data reported by the participants were summarized using descriptive statistics. Survey respondents reported the type of curriculum that they currently used, with a choice of community based curriculum versus a hospital based curriculum. A definition of a community based curriculum was provided. Other external variables that were collected included age, tenure status, teaching experience, and experience teaching in a program with a community based curriculum.

\section{Correlation Analysis}

Research questions 1,2, and 3 addressed the relationship between behavioral beliefs, normative beliefs, and control beliefs and the intention of nursing faculty intention to use service learning. These three questions were addressed by Pearson product moment correlation coefficient. The questions on the survey that were used to answer these questions came from the scaled responses to their behavioral beliefs, normative beliefs, and control beliefs. Correlation statistics determine if a relationship 
between variables exists, how strong that relationship is, and also how much several variables by themselves or in combination will affect a behavior (Gall et al., 2003).

\section{Path Analysis}

Question 4 asked, "Does the theory of planned behavior and the external variables (type of curriculum, teaching experience, and tenure status) predict the intention of nursing faculty to use service learning?" This question was addressed by path analysis using the scaled responses from the instrument. Path analysis is a method for testing the validity of a theory about causal links or relationships between two or more variables (Gall et al., 2003). A path analysis is applicable to the research question posed since it is a more powerful statistical application when the researcher is examining causal relationships between variables. In this study, path analysis was used to determine if the predictor variables were appropriate indicators of the criterion variable, and the interrelationships among predictor variables. Path analysis determined whether the theory of planned behavior was a good explanatory model for nurse educator's intention to use service learning.

\section{Summary of Chapter Three}

Chapter three has described the specific method and procedures for this research study including a description of the methodological approach and design. The description of the procedure for creating the instrument, as well as the pilot testing of that instrument were explained. Specific information concerning data collection and the procedures for protection of human subjects were described. Finally, the statistical analysis procedures were reviewed. 


\section{CHAPTER IV}

\section{RESULTS}

The purpose of this study was to apply the theory of planned behavior to determine the motivational factors that influence nursing faculty use of service learning through the application of the theory of planned behavior (TPB). The constructs from the TPB (behavioral beliefs, normative beliefs, control beliefs) in addition to external factors identified from the literature review (tenure status, teaching experience, type of curriculum) formed the predictor variables, while behavioral intention to use service learning was the criterion variable. A correlational, predictive design was used to address the research questions. Demographic data were collected as well as scale responses from the survey. Descriptive statistics were computed and the research questions were analyzed using Pearson product moment correlation coefficient and path analysis.

\section{Response Rate}

Through a stratified sampling technique, 330 questionnaires were mailed to nursing faculty members in the southeastern United States. A $48 \%$ response rate was obtained $(N=160)$. Three surveys were eliminated entirely from this study because of incomplete data, resulting in a rate of $1.9 \%$ for randomly missing data. Tabachnick and Fidell (2001) state that survey responses can be used if there is less than $5 \%$ of the data are randomly missing.

\section{Participants}

Most respondents (72.6\%) were over 40 years of age, with an average age of 51.4 years. This reflects the national trend of the aging work force in nursing education (AACN, 2005). Fifty-seven percent had more than fifteen years of teaching experience, 
with an average of 15.05 years of experience. Of the $84.5 \%$ of faculty teaching in a community based curriculum, the average number of years experience teaching in a community based curriculum was 8.12 years (Table 6 ).

Table 6

Teaching Experience of Survey Respondents

$\begin{array}{lll}\text { Characteristics } & N \quad \% \text { of respondents }\end{array}$

Teaching experience

$<5$ years

29

18.7

6-10 years

31

20.0

$11-15$ years

27

17.5

16- 20 years

25

16.1

$>21$ years

43

27.7

Currently teaching in community based curriculum

Yes

No

24

15.5

Community based curriculum teaching experience

0 years

$1-5$ years

5-10 years

27

17.4

$>10$ years

33

21.2

* Missing data for teaching experience and community based teaching experience $(n=155)$ 
In the area of educational preparation, $52.5 \%$ had attained a Master of Science in Nursing Degree, while $47.5 \%$ had been prepared at the doctoral level. The respondents had an assortment of educational preparation outside of nursing. Six respondents reported having a Master's in Business Administration, five had a Doctorate in Education, nine had a Doctorate in Philosophy in a specialty other than nursing, and three had a Master's in Public Health. Finally, only $28.4 \%$ were tenured faculty, while $35.8 \%$ percent were not on a tenure track in their current employment position. Table 7 summarizes this demographic data.

Table 7

Demographic Characteristics of Survey Respondents

Characteristics $\quad$ \% of respondents

Tenure *

Tenured

43

28.4

Not Tenured

54

35.8

Not on Tenure Track

54

35.8

Degree *

$\mathrm{PhD}$

56

35.4

DNS

19

12.1

MSN

83

52.5

* Missing data was present for tenure $(n=151)$ and degree $(n=158)$ 


\section{Pearson Product Moment Correlation Coefficient}

A Pearson product moment correlation coefficient was applied to answer research questions one, two, and three. Pearson product correlation coefficient indicates the degree that the predictor variables (behavior beliefs, normative beliefs, and control beliefs) are related to the criterion variable (intention to use service learning).

Research Question 1

Question one asked: What is the relationship between behavioral beliefs (attitude) and the intention of nursing faculty to use service learning? The correlation between behavioral beliefs and intention to use service learning was statistically significant, $r(160)=.521, p<.05$. These results suggested that when behavioral belief (attitude) scores increased, scores on behavior intention (motivation) to use service learning also increased.

Research Question 2

Research question two asked: What is the relationship between normative beliefs (peer influence) and the intention of nursing faculty to use service learning? The correlation between normative beliefs (peer influence) and intention to use service learning was statistically significant, $r(160)=.719, p<.05$. These results suggested that when normative belief (peer influence) scores increased, behavior intention (motivation) scores increased.

Research Question 3

Research question three asked: What is the relationship between control beliefs (confidence and resources) and intention of nursing faculty to use service learning? The 
correlation between control beliefs (confidence and resources) and intention to use service learning was statistically significant, $r(160)=.649, p<.05$. These results suggested that when control belief (confidence and access to resources) scores increased, scores on behavior intention (motivation) also increased.

In summary, the strongest correlation was between normative beliefs and intention $(r=.719)$ while the weakest correlation was between behavioral beliefs and intention $(r=.521)$. Table 8 summarizes the correlation results.

Table 8

Correlation Analysis of Theory of Planned Behavior Constructs

\begin{tabular}{llll}
\hline Variable & BB & CB & NB
\end{tabular}

BI

$.521^{*}$

$.649^{*}$

$.719^{*}$

$N$

160

160

160

NB

$.550^{*}$

$.688^{*}$

$N$

160

160

CB

$.500^{*}$

$N$

160

* Correlation is significant at the .05 level

( $\mathrm{BB}=$ behavior beliefs, $\mathrm{NB}=$ normative beliefs. $\mathrm{CB}=$ control beliefs. $\mathrm{BI}=$ behavior intention)

The Pearson product correlation coefficient also revealed significant positive relationships between the belief constructs. There was a significant relationship between behavioral beliefs and normative beliefs, $r(160)=.550, p<.05$. When behavior belief (attitude) scores toward the intention to use service learning increased, scores on normative beliefs (peer influence) increased. There was also a significant relationship 
between behavioral beliefs and control beliefs, $r(160)=.500, p<.05$. When behavior belief (attitudes) scores toward the intention to use service learning increased, control belief (confidence and access to resources) scores also increased. Last, there was a significant relationship between normative beliefs and control beliefs, $r(160)=.688, p<$ .05 . When normative belief (peer influence) scores toward the intention to use of service learning increased, control beliefs (confidence and access to resources) scores increased. The highest correlation within the constructs was between normative beliefs and control beliefs.

When examining and comparing means on the behavioral belief items, the items that received the most positive ratings were 'increase student learning' $(M=6.10)$, 'useful' $(M=6.09)$, and 'interesting' $(M=6.10)$. The scores on survey items that received the lowest rating were 'simple' $(M=3.87)$, 'easy' $(M=4.26)$, and 'covering nursing content' $(M=3.49)$. The mean scores on normative beliefs were also examined and the items that had the most positive scores were 'people whose opinion I value' $(M=$ 5.72), 'philosophy of life' $(M=5.68)$, and 'personal beliefs' $(M=5.67)$. Survey items that received the lowest scores from normative beliefs were 'parents' $(M=3.32)$, 'family' $(M=3.61)$, and 'religious beliefs' $(M=3.86)$. Finally, the items on the survey that received the highest scores for control beliefs were 'university mission' $(M=6.06)$, 'knowledge' $(M=5.52)$, and 'control over what they do' $(M=5.70)$. The survey items that received the lowest control belief scores were 'the prescribed curriculum' $(M=$ 2.92), 'professional regulations' $(M=3.09)$, and 'travel reimbursement' $(M=3.30)$. 


\section{Path Analysis}

Many researchers have used multiple regression analysis when using the theory of planned behavior, which renders a prediction of relationships. In this study, the technique of path analysis was used to test the validity of the theory of causal links between the variables. It also allowed for direct causal effects to be estimated using Beta weights $(\beta)$ as path coefficients as well as indirect effects, occurring when one variable affected another thereby influencing the results (Mertler \& Vannatta, 2002). Path coefficients represent the magnitude of influence of one variable on another in the path model. Standardized coefficients reflect which predictor variable has the greatest direct influence on the criterion variable. Unstandardized coefficients indicate the magnitude of a particular path (Munro, 2005).

Research Question 4

A path analysis was applied to the data to address research question four: Does the theory of planned behavior and the external variables (type of curriculum, teaching experience, tenure status) predict the intention of nursing faculty to use service learning? The proposed model of behavior intention considered the intention of nursing faculty to use service learning to be a function of tenure status, curriculum, experience, behavioral beliefs, normative beliefs, control beliefs and a disturbance term. The disturbance term, or residual error, reflects the unexplained variance (the effect of unmeasured variables, plus measurement error).

Figure 3 presents the proposed model. The disturbance term is assumed to be statistically independent of the three external variables (tenure status, type of curriculum, 


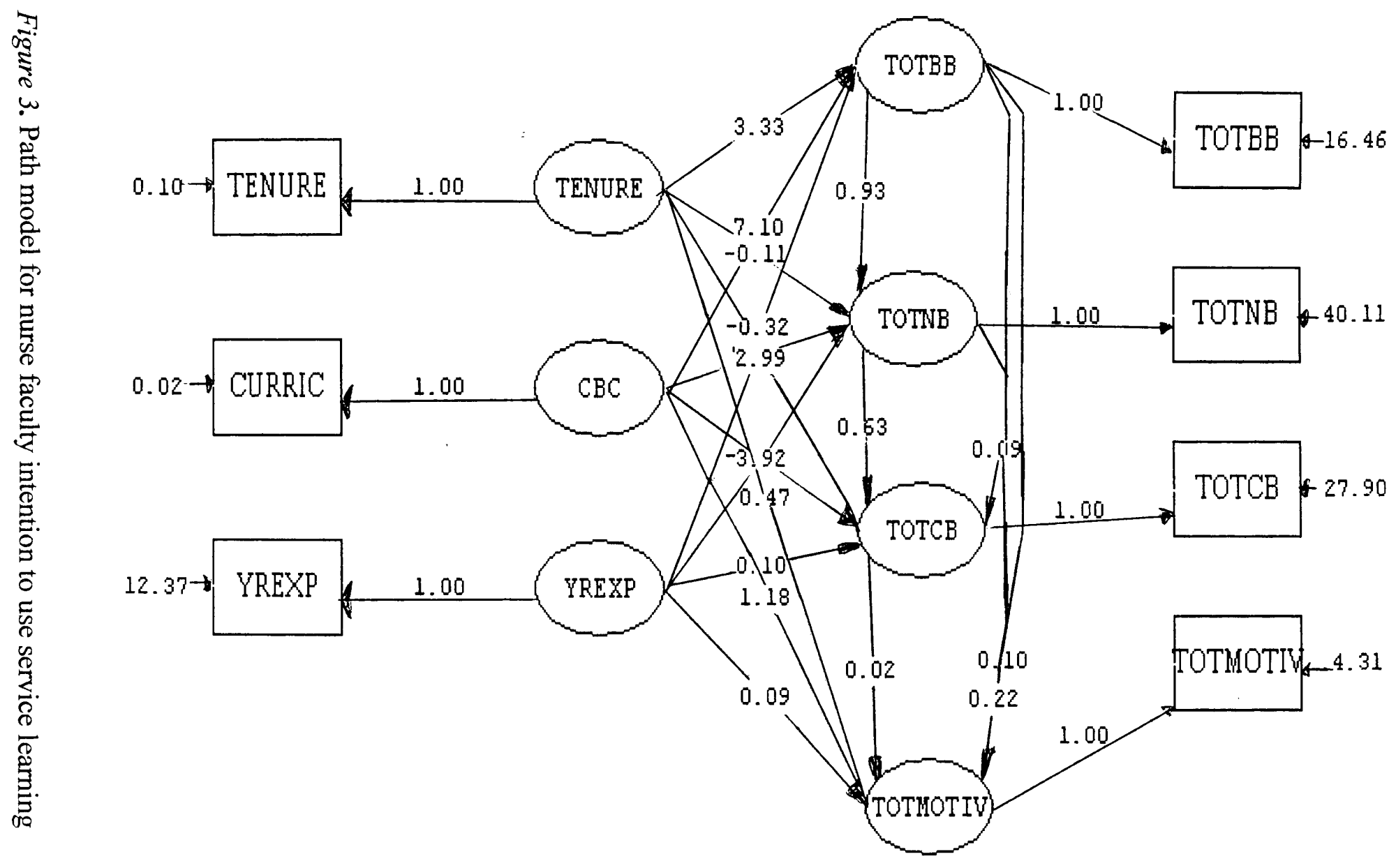


and teaching experience) and is also assumed to be independent of the disturbance terms attached to behavioral, normative and control beliefs.

The computer program LISREL 7 (Jöreskog \& Sörbom, 2005) was utilized to analyze the proposed theory of behavior intention model. LISREL consists of a structured equation model and a measurement model (Pedhazur, 1982). The structured equation model refers to the relationships among the external variables (tenure, curriculum, and years of teaching experience) and the theory of planned behavior variables (behavioral beliefs, normative beliefs, control beliefs, and behavior intention). These are represented by ellipses in the path diagram. The measured model specified the relationships between the unobserved and observed, or latent and manifest variable. The analysis identified latent variables, those not measured by direct observation.

Direct pathways. Three direct paths appeared to have the highest magnitude of influence on the criterion variable. Normative beliefs had the greatest direct influence on intention to use service learning ( beta $=.67)$, followed by behavioral beliefs $($ beta $=.20)$, and teaching experience $($ beta $=15)$. However, control beliefs did not have a strong direct influence on nursing faculty intention to use service learning $($ beta $=.06)$, nor did tenure status $($ beta $=.07)$ or type of curriculum $($ beta $=.08)$. The magnitude of normative beliefs on intention was over three times as great as that of any other predictor variable (beta $=$ .67). The results of the path coefficients in the standard form are shown in Table 9.

Indirect pathways. Several indirect pathways were found to affect the intention to use service learning by influencing other predictor variables. Figures four, five, and six depicts the relationships between the variables and the indirect effects on behavioral, normative, and control beliefs. 
Table 9

Path Coefficients in Standard Form for the Model Variables

Variable

BB

NB

CB

BI

Tenure

0.26

$-0.01$

0.18

0.07

Curriculum

0.24

0.15

0.10

0.08

Experience

$-0.27$

$-0.12$

0.06

0.15

BB

0.60

0.07

0.20

NB

0.75

0.67

CB

0.06

( $\mathrm{BB}=$ behavior beliefs, $\mathrm{NB}=$ normative beliefs, $\mathrm{CB}=$ control beliefs, $\mathrm{BI}=$ behavior intention)

Behavior beliefs and normative beliefs had a strong path to each other $($ beta $=$ .93 ), and normative beliefs and control beliefs had a strong path to each other (beta $=$ .63). However, behavioral beliefs and control beliefs displayed a weak path to each other $($ beta $=.09)$. Predictor variables outside of the TPB constructs were also determined to indirectly affect nursing faculty intention to use service learning through an influence on the TPB constructs.

Behavioral beliefs were influenced by all three external variables, which in turn, affected the magnitude of behavioral beliefs on behavior intention. Tenure had a significant positive influence on behavioral beliefs (beta $=3.33)$. Faculty with tenure status had stronger, positive behavioral beliefs (attitudes) towards behavior intention. The type of curriculum, specifically a community based curriculum, had significant positive 
influence on behavioral beliefs (beta $=7.10)$. Faculty who taught in a community based curriculum had stronger, positive behavioral beliefs (attitudes) related to behavior intention to use service learning. Finally, years of teaching experience had a significant negative effect on behavioral beliefs $($ beta $=-0.32$ ). Faculty with more experience had weaker behavioral beliefs (attitude) towards behavior intention, which can be re-stated that faculty with less teaching experience have more positive attitudes towards intention to use service learning. Figure 4 shows the indirect paths associated with behavioral beliefs and intention.

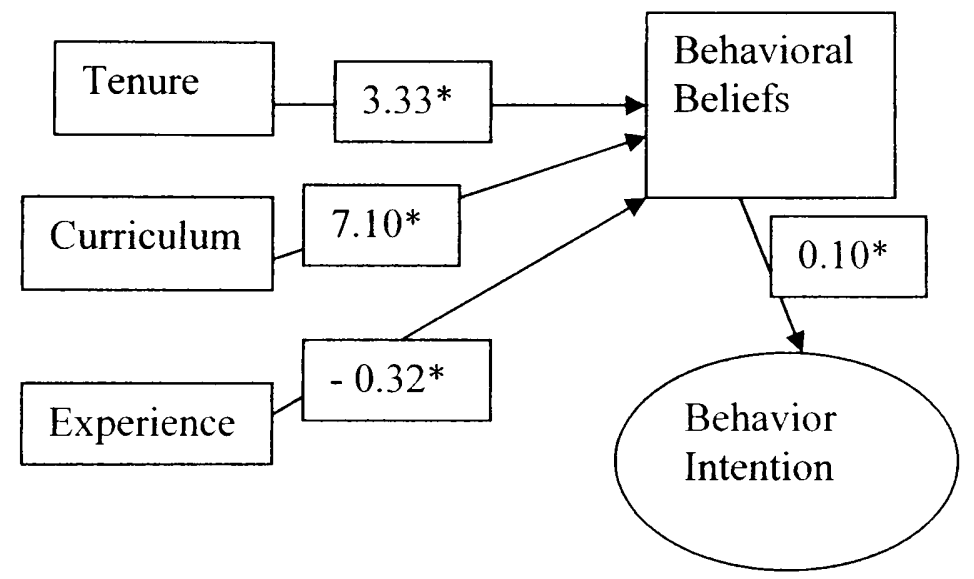

Figure 4. Indirect paths associated with behavioral beliefs and behavior intention The only significant indirect path that influenced normative beliefs was the type of curriculum $($ beta $=7.16)$. Faculty who taught in a community based curriculum were influenced by their peers in their intention to use service learning. Tenure (beta $=-0.11$ ) and teaching experience $($ beta $=-0.22)$ had minimal, but negative influences on normative beliefs. Figure 5 shows the indirect paths associated with normative beliefs. The third construct of the TPB, control beliefs, also had only one indirect path that had a significant influence on that construct. Tenure status $($ beta $=2.99)$ was a positive 


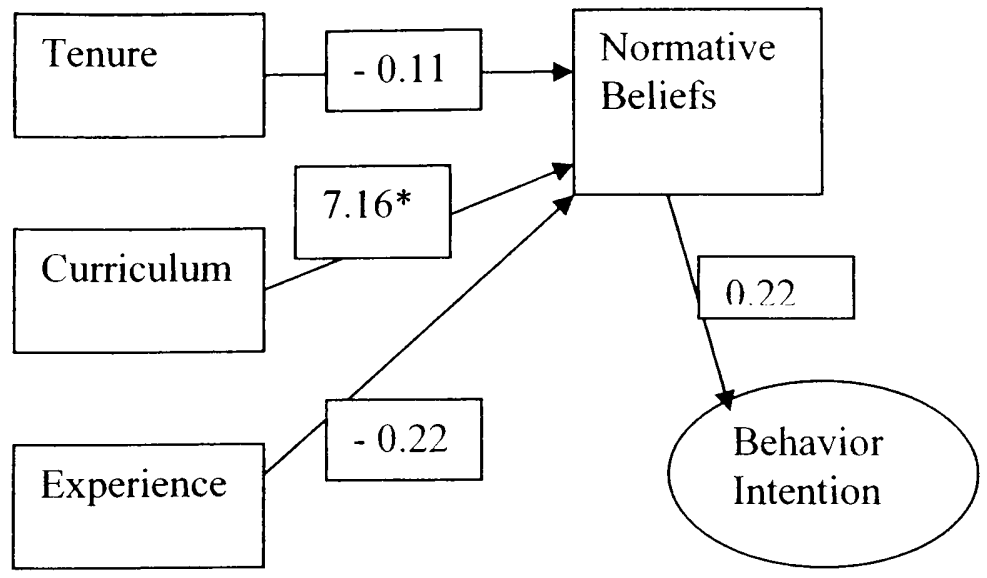

Figure 5. Indirect paths associated with normative beliefs and behavior intention significant influence, however, control beliefs were not a significant path to behavior intention. Faculty with tenure status indicated a greater confidence towards intention to use service learning than faculty who did not have tenure status. The type of curriculum $($ beta $=3.92)$ and teaching experience $($ bet $a=0.68)$ were not significant influences on control beliefs. The schematic of this indirect path can be found in Figure 6.

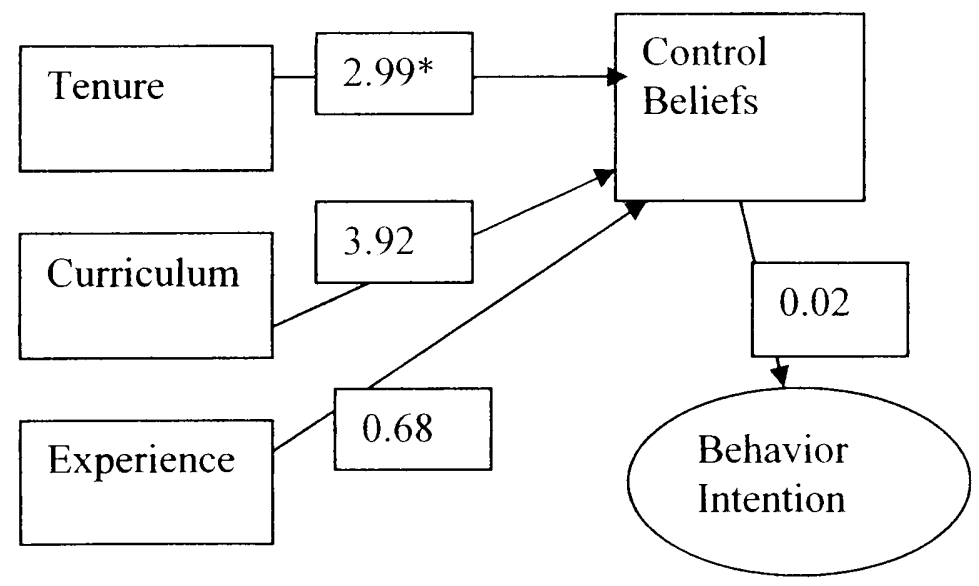

Figure 6. Indirect paths associated with control beliefs and behavior intention

The path coefficients, standard errors, and $t$-values are shown in Table 10. The standard error is a measure of the precision of the parameter estimate. 
Table 10

Path Coefficients in Unstandardized Form

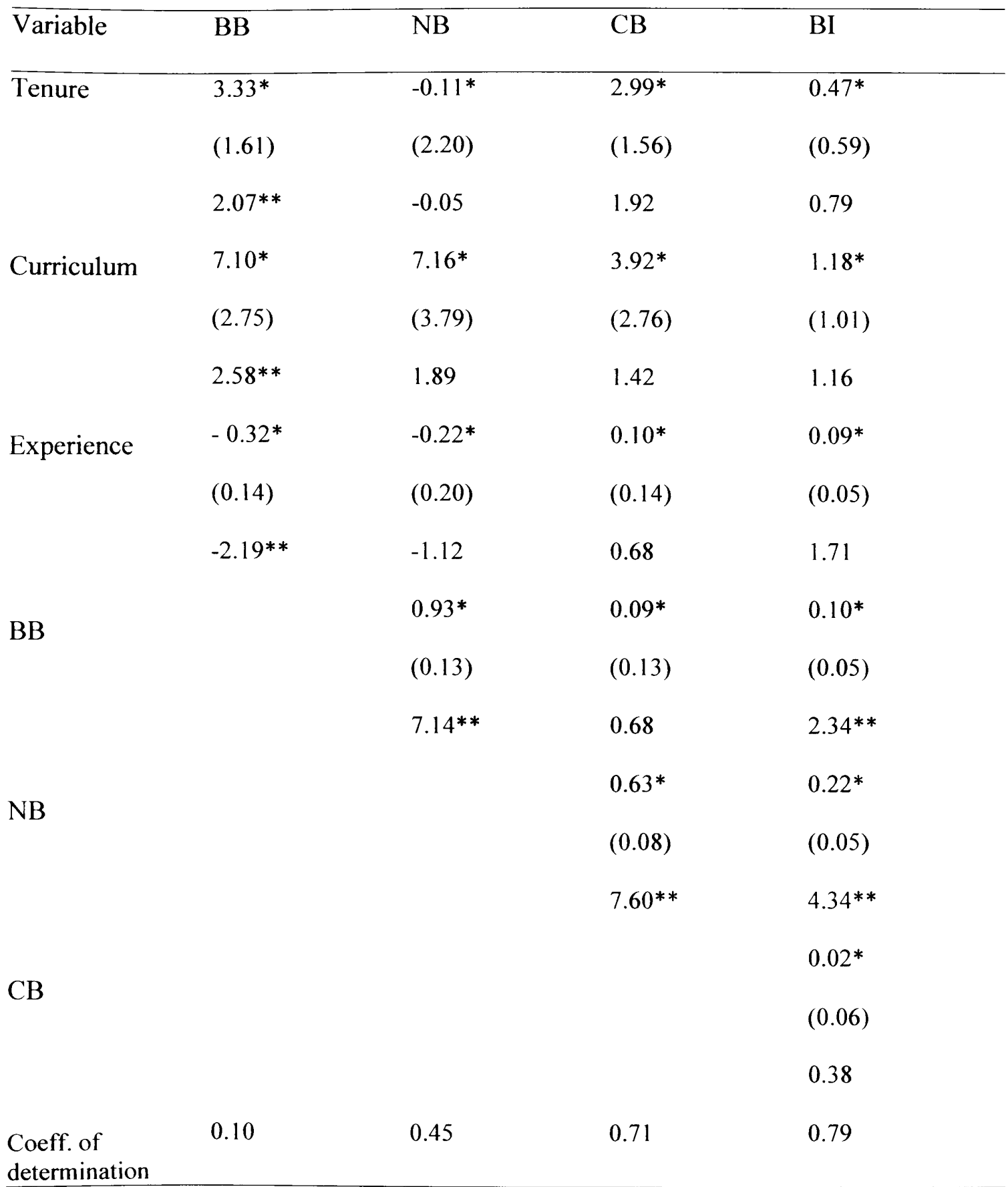

( $\mathrm{BB}=$ behavior beliefs, $\mathrm{NB}=$ normative beliefs, $\mathrm{CB}=$ control beliefs, $\mathrm{BI}=$ behavior intention)

* Path coefficient, a standardized regression coefficient, beta (standard error)

Chi-square $=0.0, p=1.00 \quad t$-value $=$ beta/standard error

** $t$-value is significant 
The $t$-value for a parameter is defined as the parameter estimate divided by its standard error. Parameters whose $t$-values are larger than two in magnitude are normally judged to be different from zero (Jöreskog \& Sörbom, 1989).

Summary of path analysis. The results of the path analysis indicated that there was a strong, direct relationship between two of the three constructs of the theory of planned behavior, as previously noted in Table 9. First, the direct path for normative beliefs (peer influence) and the intention of nursing faculty to use service learning (beta $=.67)$ suggested that peers such as administrators, colleagues, and students had a significant impact on the magnitude of nursing faculty intention to use service learning. Second, there was a direct, positive relationship between behavioral beliefs (attitude) and the intention of nursing faculty to use service learning $($ beta $=0.20)$. As behavioral beliefs (attitude) increased, there were strong indications that intention of nursing faculty to use service learning increased. However, a weak direct path between control beliefs and the intention of nursing faculty to use service learning (beta $=.06)$ emerged. The impact of control beliefs (confidence and resources) was not a strong predictor of intention to use service learning.

Moreover, the external variables (experience, tenure status, type of curriculum) showed direct paths to behavior intention. Teaching experience had a direct relationship to behavior intention $($ beta $=.15)$. Increased tenure status $($ beta $=.07)$ and a community based curriculum (beta $=.08$ ) had slight, yet positive relationships with the intention to use service learning.

The final research question for this study asked if the theory of planned behavior constructs (normative beliefs, behavioral beliefs, and control beliefs) and the external 
variables (type of curriculum, teaching experience, and tenure status) would predict the intention of nursing faculty to use service learning. The proposed model was confirmed using path analysis, indicating that the constructs from the theory of planned behavior, and the external variables were statistically significant in predicting nursing faculty intention to use service learning. Seventy-nine percent of the variance of nursing faculty intention to use service learning can be explained by the proposed model (constructs from the theory of planned behavior, and the external variables).

\section{Summary of Chapter Four}

The interpretation, analysis, and evaluation of the research findings were presented in chapter four. Tables describing the demographic data of the sample and the results of the Pearson product moment correlation coefficient, as well as and standardized and unstandardized path coefficients were included in this chapter. 


\section{CHAPTER V}

\section{DISCUSSION}

This study drew from prior research on service learning and the theory of planned behavior (TPB) to examine the pedagogical choices of nursing faculty use of service learning in their undergraduate programs. The application of the theory of planned behavior to a specific nursing population in an educational setting expanded on prior research using the TPB to examine motivational factors that influence pedagogical choices by educators. The path model provided an estimation of the magnitude and significance of causal relationships between the TPB constructs (behavioral beliefs, normative beliefs, control beliefs), external variables (tenure status, type of curriculum, teaching experience) and the intention to use service learning.

The data for this study were collected through surveys of nursing faculty members who teach in universities that are members of the Southern Association of Colleges and Schools (SACS) and whose School of Nursing are members of the American Association of Colleges of Nursing (AACN). The schools were also accredited by either the National League for Nursing Accrediting Commission (NLNAC) and/or the Commission on Collegiate Nursing Education (CCNE). Data were analyzed through a combination of correlations and path analysis in order to determine the factors that influence nurse educators use of service learning pedagogy.

Four research questions guided this study. (a) What is the relationship between behavioral beliefs and the intention of nursing faculty to use service learning? (b) What is the relationship between normative beliefs and the intention of 
nursing faculty to use service learning? (c) What is the relationship between control beliefs and the intention of nursing faculty to use service learning? (d) Does the theory of planned behavior and the external variables (type of curriculum, teaching experience, tenure status) predict the intention of nursing faculty to use service learning?

Chapter V provides an analysis of data results, discusses how the results relate to prior research on the use of service learning, and reviews the application of the theory of planned behavior as motivational theory in general and specifically to the target population of nursing faculty. Limitations of this study are noted, and the implications for nursing and for higher education are discussed. Recommendations for future research are reported.

\section{Evaluation of Study Results}

This study was designed to apply the theory of planned behavior to answer four research questions on nursing faculty motivation to use service learning pedagogy. It demonstrated rigor in several areas that allowed for the results to be trusted in the defined context. This study extends the application of TPB to the motivation of nurse educators' use of service learning pedagogy. This study was the second (found to date) where the TPB was used to study faculty intention to use service learning. Finally, research on nursing faculty use of service learning was limited, thus this study added to the body of research in the area of service learning and nursing education.

The strict adherence to the theoretical guidelines for instrument creation, including the group discussions and pilot test of the survey, yielded a strong alpha 
coefficient for the measured items on the instrument. The instrument was consistent with how similar instruments had been constructed and used in prior research applying the theory of planned behavior.

Applying the statistical application of Pearson product correlation coefficient to answer three of the research questions was appropriate and consistent with prior research using the TPB. Although most studies with TPB used multiple regression to answer research questions and test hypotheses, path analysis has been used in recent research. Ajzen (personal communication, 2004) indicated that path analysis was appropriate and effective in providing explanations for possible causal relationships within TPB constructs.

The response rate of $48 \%$ was considered low, but adequate in mailed survey research, thus strengthening the believability of this study. Dey (1997) reported that nationwide, mailed survey response rates have declined from $65 \%$ in the 1960 's, to $21 \%$ in the 1990 's. The survey of faculty from a representative sample of institutions of higher education in the Southeastern United States, as well as the identification of two definitive types of curriculum prevalent in nursing education (community based versus hospital based) also lends credibility to the study results.

\section{Discussion of Results}

Based on the responses from 160 faculty members who teach nursing in 20 diverse institutions of higher education in the Southeastern United States, a multifactorial pattern to explain the use of service learning by nurse educators emerged. Behavioral beliefs (attitudes), normative beliefs (peer influence), and control beliefs (confidence and resources) all influenced nurse educator intention to 
use service learning. The impact of the type of curriculum, tenure status, and the teaching experience of the faculty were also noted.

\section{Relationship to Prior Research}

The results of the path analysis indicated that there was a statistically significant relationship between normative beliefs and nurse educator intention to use service learning. Normative beliefs (peer influence) showed the strongest path to nursing faculty intention to use service learning. Item analysis revealed that items related to 'peers whose opinion was valued', and 'personal philosophy and beliefs systems' received the highest ratings. Similar results have been obtained by other researchers. Abes et al. (2002) and Hayden (2004) reported that peers influenced faculty decisions to use service learning.

However, the results of item analysis from the correlation suggested that while normative beliefs (peers) were significant, it was specific peers, described as those whose opinion the respondent valued, as being most significant $(M=5.72)$. 'Personal beliefs systems' and 'philosophy of life' were also significant indicators of use of service learning in this study. These results are corroborated in research applying TPB to other professions. For example, Bragg (2000) found that normative beliefs influenced faculty to use service learning, as did Hammond (1994), Hayden (2004), Hinck and Brandell (2000), and Price (2003). This suggests that there exists a more intrinsic basis for faculty motivation to use service learning; the motivation came from within themselves and their own philosophy of life rather than academic peers.

There was a significant relationship between behavioral beliefs and the intention to use of service learning by nurse educators in the correlation as well as the 
path analysis. This outcome suggested that nurse educator beliefs concerning service learning (its usefulness, appropriateness, and the ability to cover nursing content) has an effect on individual intention to use service learning. These results are consistent with prior research on educator attitudes towards pedagogical choices in other professions. Abes et al. (2002), Hayden (2004), and Pribbenow (2002) all concluded that service learning provided enhanced student learning, while Hammond (1994) reported that using service learning brought relevance to course material for students, and Bragg (2000) reported that faculty put student learning above other variables when making pedagogical decisions.

The results of item analysis from the correlation indicated that the respondents believed that student learning was important; however, the item analysis of responses to normative belief items showed that nurse faculty did not consider the impact from students as being highly influential in their decisions to use service learning. Therefore, it appears that while nursing faculty believe that service learning is a beneficial pedagogy to employ, student influence did not play a substantial role in the decision to use it.

In general, control beliefs (confidence and resources) were shown to be statistically significant influences on nurse educator intention to use service learning in the correlation analysis, but not in the path analysis. This may be explained by analyzing the indirect pathways found in the path analysis. In the correlation analysis, control belief items related to the mission of the university received the highest ratings, followed by faculty belief that they have the freedom, knowledge, and the ability to use service learning in their classrooms. While only one prior study cited 
university mission as the most significant control indicator (Hawks, 1999), other researchers have found that the university mission played a major role in supporting faculty endeavors to use alternative pedagogy, such as service learning (Dee, Henkin, \& Pell, 2002; Euster \& Weinbach, 1994). However, in one study, Abes et al. (2002) indicated that there was no significant difference in motivation that related to institutional support.

Nurse educator beliefs related to personal knowledge and the ability to use service learning were noteworthy. Overall, items on the survey related to having the knowledge to use service learning, as well as the conviction that it would be possible for them to implement service learning, were important indicators for nursing faculty intention to use service learning. This was similar to findings by other researchers (Abes et al., 2002; Bragg, 2000; Price, 2003).

Although clerical support, travel money, and release time were included in this study, these items received the lowest ratings for control beliefs. Hammond (1994) reported that workload was not an important indicator, but lack of release time and the availability of resources were barriers for faculty use of service learning. Studies by Abes et al. (2002), Price (2003), and Ward (1998) indicated that factors such as a lack of release time for class preparation, funding, and the lack of rewards for using service learning were major barriers. When analyzing the results specific to nurse educators, it appeared that nursing regulations and curricular restraints were not important indicators of the intention to use service learning. Items on the survey related to clerical support and money were the lowest rated items compared to faculty knowledge and confidence in using service learning. 
The results of the path analysis determined that the type of curriculum indirectly impacted the use of service learning by influencing other variables, specifically behavior beliefs and normative beliefs. Gelmon et al. (1998) also determined that curriculum and the use of service learning were closely associated with each other. In addition, Gelmon et al. (1998) and Martin (1994) reported that health and service related professions were more likely to engage in service learning.

Previous researchers reported teaching experience in demographic discussions. In this study, teaching experience showed a relatively strong path to the intention to use service learning as well as an indirect path towards intention to use service learning. As teaching experience increased, behavior beliefs (attitude) and normative beliefs (peer influence) towards intention to use service learning decreased, and control beliefs (confidence and resources) increased slightly.

Tenure status showed a positive, direct path to nurse educators' intention to use service learning; however, it also showed an indirect path to intention through other predictor variables. As tenure status increased, the magnitude of behavioral beliefs (attitude towards the use of service learning) and control beliefs (confidence and resources) increased. These results conflict with prior researchers (Abes et al., 2002; Hammond, 1994; Robinson \& Barnett, 1996) who reported tenure status did not influence the use of service learning. However, these researchers analyzed their data with $A N O V A$ and Chi square. Perhaps the path analysis allowed a more precise identification of the interrelationships compared to other statistical analyses. 


\section{Inferences from Path Analysis}

The three basic conditions that need to exist for path analysis to provide meaningful results in this study were addressed. The sample size was adequate, the variables were well measured, and attempts to include causal variables resulted in three external variables which were identified from the literature review (Gall, Gall, $\&$ Borg, 2003). However, only .79 of the variance was explained by the proposed model, indicating that there may be other variables not identified in this study. Therefore, several general but guarded conclusions can be made from the path analysis results. The path analysis yielded richer findings than the correlation analysis. The path analysis helped to investigate the direction and magnitude of the relationships of the predictor variables on the intention to use service learning (the criterion variable), and based on the path analysis, a clearer picture emerged to explain nursing faculty intention to use service learning.

The most striking result was the dominance of the normative beliefs in this study. In the correlation analysis, normative beliefs showed the strongest correlation to the intention to use service learning, and in the path analysis, the magnitude of the effect of the normative beliefs on intention to use service learning was more than three times as great as that of the other predictor variables. This finding, coupled with the item analysis results from the correlation, suggested that peer influence was specific to the respondent and not necessarily academic peers. This finding indicated that there may be intrinsic influences that were not uncovered in this study. The path analysis results also indicated that as experience increased, the magnitude of normative beliefs (influence from their peers) dccrcascd. This suggests that there 
might be a more intrinsic motivation to nurse educator choices of pedagogy, similar to findings by Hayden (2005) who found that normative beliefs influenced faculty from a variety of professions.

Nursing faculty who teach a community based curriculum may be more amenable to using service learning in their classes. This is congruent with the basic philosophy of service learning, which includes a collaborative relationship between academia and the community to address the needs of society. However, since employing a community based curriculum impacts faculty normative beliefs (who their peers are), it may be important to look deeper into the schools' relationship with the target community. This may help to determine who the specific peers are who were reported in this study to influence nursing faculty pedagogical decisions.

Boyer (1990) spoke of a shift in expectations for faculty from a teaching focus to a scholarship focus. In this study, tenure status had a positive relationship with faculty attitude, level of confidence, and the belief that resources are available for the use of service learning. This suggests that faculty who had tenure status were more likely to have a positive attitude towards the use of service learning. Perhaps these faculty members are more aware of the steps in accruing grants and financial support for service learning projects, while non-tenured faculty may not have the expertise to navigate that aspect of higher education. Also, tenured faculty may feel more comfortable taking pedagogical risks since they have greater security in their academic position.

The results of this study indicated that nursing faculty are aging; $73 \%$ were over the age of 40 and approximately $61 \%$ had more than 15 ycars of teaching 
experience. In the path analysis, as teaching experience increased, the magnitude of faculty attitude towards using service learning decreased. This may be related to faculty who shift their attention towards scholarship, or it may reflect a type of complacency. Regardless, this is discouraging since with repetition of any activity comes greater expertise. A longitudinal study by Euster and Weinbach (1994) determined that faculty have progressively valued scholarship more over the past decade, but also indicated a continued commitment to community service. Perhaps nursing faculty are seeking to find a balance between scholarship and service in their professional goals. Finally, since less experienced faculty appear to be open to new pedagogy such as service learning, administration can facilitate faculty expertise in implementing new pedagogy, as well as encourage and support scholarship endeavors in this area through early mentoring programs for new faculty members.

\section{Revisiting Assumptions}

This study was based upon several philosophical and structural assumptions. These assumptions have been re-visited and addressed in relation to the study results.

Assumption 1: The faculty who work in schools that are members of the American Association of Colleges of Nursing (AACN) will be influenced and guided by position statements from this organization. There were a substantial percentage of respondents who were currently teaching in a community based curriculum $(82.2 \%)$, which demonstrates a positive response to the position statement from the $\mathrm{AACN}$ to restructure nursing curricula towards community needs.

Assumption 2: The curriculum in nursing programs is tightly structured and partially scripted due to the mandatory regulations set forth by the national licensing 
exam that all nursing students must pass in order to practice as a Registered Nurse in the United States. This assumption was addressed by including professional regulations in the definition of service learning as well as in specific items on the survey. Although the results of the mean scores on item analysis from the correlation analysis on the influence of professional regulations on the use of service learning were significant $(M=2.92)$, they were one of the lowest scoring items on the instrument. It appears that faculty considered professional regulations in their decisions, but they were able to work within any constraints that may arise. Considering that the importance of student learning played in the responses in this study $(M=6.19)$, faculty appear to have indicated that there is a more philosophical foundation to their pedagogical decisions than simply teaching students to take a final exam.

Assumption 3: Nursing faculty have some control over decisions in how they teach in the curriculum. Nursing faculty who participated in this study reported that they have some control over decisions in how they teach in the curriculum. There was a significant positive correlation between control beliefs and the intention to use service learning, especially from intrinsic beliefs such as knowledge the ability to use service learning if they chose to, and the belief that it was possible to use service learning in their classrooms.

\section{Limitations of Study}

Several limitations govern the interpretation of the results of this study. The nature of self-report must be considered since there were no methods to confirm (or disconfirm) the accuracy of participants' responses regarding the usc of scrvicc 
learning. The self-report of intention to use service learning is different than the actual behavior of using service learning, which cannot be measured using a selfreport format.

There were barriers to access of the target sample stemming from the use of faculty lists provided by the participating schools and/or websites, which may not have been completely accurate. In addition, several hurricanes that occurred during the data collection period created an access dilemma both through the postal mail and electronic mail.

The use of a single theoretical perspective to investigate motivation may limit the appearance of significant findings not measured with the TPB. Other variables such as level of education may influence the criterion variables; however, they were not addressed in this study. The results cannot be generalized beyond nursing programs in the Southeastern United States that fit the set criteria, thus eliminating programs in other areas of the country.

There were also problems with the definitions of service learning and community based curriculum. The attempt in this study to limit the influence of numerous definitions of these terms was not totally successful, resulting in confounding responses to some items on the survey. The individual interpretation of these central terms may limit the ability to generalize the results to other populations.

This study examined the use of service learning by nursing faculty only, thus excluding other educational specialties. This study further focused on the nursing faculty practicing in undergraduate programs in the southeastern United States. It examined multi-factorial issues that influence nursing faculty decisions to use service 
learning in their classes instead of focusing on one aspect of motivation. Although the use of innovative pedagogy is inclusive of service learning, this study solely examined the use of service learning pedagogy. Only one theoretical model (the theory of planned behavior) was applied to the data, noting that other theories may apply, but the theory of planned behavior was specifically chosen for its broad application to a multitude of factors that influence behavior, and its ability to evaluate the influence of each construct individually as well as in aggregate.

Implications for Nursing and Higher Education

In spite of the limitations, the results of this study have implications for practice and policy at institutions of higher education. Historically, the concept of public service in a university mission began with the 1862 Morrill Act and land grant universities, and was further developed through the junior and community college systems. Connecting service to learning continued to evolve over the past century, and in 1990, the government passed the National Community Service Act followed by the Community Service Trust Act in 1993, to address the numerous social challenges facing the country by using community resources (Bailey, Carpenter, \& Harrington, 2002; Grey et al., 2000).

Higher education responded to these programs with their own plan to re-direct the focus of community involvement by academia. Some of these foundational changes in education stem from the Wingspread Principles of Good Practice for Combining Service and Learning (The Johnson Foundation, 1989). This was a two year project completed by more than seventy-five regional and national organizations fully engaged in community service and experiential education. These principles have 
become the foundation of effective service learning programs, and include principles such as engaging people in responsible actions for the common good, and a commitment to diverse populations (The Johnson Foundation, 1989).

In 1998, the $4^{\text {th }}$ Report of the Pew Health Professions Commission entitled Health Profession Schools on Service to the Nation identified service learning as a key competency for students, and emphasized the need to strengthen partnerships between health profession schools and communities to address unmet health needs. Examples of competencies recommended by the commission included learning experiences in the curriculum that included social and environmental issues.

The results of this study support the recommendations set forth by federal government initiatives and the Pew Foundation, and confirm community based curricula and the use of service learning in schools of nursing. Higher education must continue to address the needs of nursing programs to facilitate this transition to a community focus. In fact, because service is a pillar in many higher education institutional mission statements, service learning may also fit institutional missions. The results of this study suggested that faculty who participated in service learning did so because of an intrinsic belief that it was important for them to expose students to this aspect of education. It may be encouraging to higher education administration that the faculty in this study were aware of the university mission, and were working to actualize the service portion of the mission. Involvement with organizations such as Campus Compact and Community Campus Partnership for Health (Seifer, 2006) could be facilitated and supported by university administration to help meet the goals of community involvement. This would be a means to recruit and retain faculty who 
are committed to work in a university where their personal vision and mission are congruent with that of the university.

The respondents in this study reported that fiscal support was not as important as their own knowledge of service learning and their comfort level in using it in their courses. This information could help in the design of faculty development programs on service learning to facilitate its use in other universities with nursing programs or with other professional educators within the same institution. It could result in expanded professional development programs to include collaboration between health-related disciplines in the design and implementation of service learning pedagogy to improve services to the community.

In the path analysis, faculty behavioral beliefs (attitude) had a fairly strong, positive relationship with the intention to use service learning, and tenure status indirectly impacted those attitudes. Assisting faculty to achieve tenure status may facilitate the use of service learning. Recruiting and retaining quality nursing faculty is imperative to provide a quality education for students that includes meaningful service to the community.

Normative beliefs (peer influence) were the strongest direct path to nursing faculty intention to use service learning in the path analysis, although the identity of specific peers influence was not determined in this study. However, through the item analysis from the correlation, there was an indication that those peers had a personal origin for each respondent. The culture of a school and university may play a major role in faculty peer groups, and administration may be able to facilitate positive relationships among the faculty, staff, students, and community. Since the magnitude 
of normative beliefs (peer influence) diminished as the faculty member gained experience, it may also be important to mentor new faculty into a university culture of service and community involvement. Or, as faculty gain experience, the natural reinforcers inherent in using effective pedagogy take over so that peer influence and encouragement is less of a factor in faculty decisions to use service learning.

When nursing education moves into community settings, the practice of nursing has a stronger emphasis on wellness and prevention of disease. When nursing students are exposed to community-based healthcare while in school, it may raise their social consciousness and civic awareness about influential social issues that exacerbate illness and injury. This perspective on healthcare would influence the focus of nursing practice but also the general approach to health and illness, perhaps leading to more students seeking employment in the community when they graduate from college.

\section{Recommendations for Future Research}

Although the theory of planned behavior has been used extensively in educational research, repeated studies using the TPB in nursing and specifically with service learning pedagogy would help validate both the theory of planned behavior and service learning pedagogy. Any future research on service learning would benefit from setting a clear definition of service learning and community based curriculum. Recommendations for nursing practice include the identification of activities that faculty believe constitute service learning, which would also help further clarify the definition of service learning in nursing education. 
In this study, normative beliefs, in particular individual beliefs and their philosophy of life, were highly correlated with nursing educators' intentions to use service learning. During instrument development, participants in the group discussions emphasized that they used service learning because of intrinsic influences. In future research, it may be beneficial to examine the correlation between the intention to use service learning and the actual behavior of using service learning. This could be achieved through the administration of a survey to measure the intention to use service learning followed by direct classroom observation of teaching practices.

Another avenue of research could be to replicate the study to examine the specific issues that may arise at institutions by type, either a public, private, or religious affiliated institutions. Perhaps the specific type of institution would be predictive of the use of service learning by its philosophy or by the faculty who are drawn to work there. It might be particularly important to replicate this study in the community college setting because service to the surrounding community arose from the community college and junior college system. Although the results of this study can not be generalized beyond the target population and setting, replication of the study with nurse educators in a different part of the country (i.e., the Southwestern United States) may yield different results.

Another interesting area that could be investigated in future studies is the influence of faculty educational background on the intention to use service learning. It is common for nursing faculty to come to the education arena with a sound clinical foundation; however, they may not have extensive training in teaching methodology 
unless they have taken education courses or earned a degree in education. Thus, many nursing faculty teach the way that they were taught. This variable may explain some of the $21 \%$ variance that was not included in this model.

Nursing is a practice profession with clinical experiences that play a central role in the learning process. There are other disciplines such as physical therapy and occupational therapy that have structured learning experiences in practical settings. The replication of this study with these disciplines would add to the body of research on the status of the $21^{\text {st }}$ century goals specified by the Pew Foundation.

\section{Conclusion}

This study was designed to test the effectiveness of components of the theory of planned behavior in predicting nurse educator's intentions to use a best practice in the education of nurses. The theory was of some value in predicting faculty intentions to use service learning pedagogy. The determinant of normative beliefs most strongly predicted faculty intention followed by behavioral beliefs. In this theoretical model, the control belief determinant was not as strong a predictor of faculty intention use of service learning pedagogy.

The field of nursing education is in the midst of a paradigm shift from hospital-based curricula to community based curricula. Some faculty may view the fact that their students are having clinical experiences in places such as community clinics as an example of service learning. In contrast, the service learning community views service learning pedagogy as requiring an explicit learning contract between the student nurse and the community organization complete with an evaluation of the learning outcomes. 
Given that .79 of the variance can be explained by the theory, a possible explanation for the TPB's relative lack of predictive value in this study may be that faculty interpreted the criterion variable (service learning) too broadly. In future research, the identification of a clearer definition of service learning activities in nursing may provide a better test of the theory. There may be factors that were not hypothesized as external variables in this path analysis model that still need to be identified. For example, prior training of faculty members was not included as an external variable. Future research may reveal that nurse educator exposure to educational pedagogy may be a factor that influences faculty intention to use service learning.

The ability to incorporate external variables outside of the predictor variables of the TPB (behavioral beliefs, normative beliefs, and control beliefs) is one of the strengths of this model. In this study, the external variables (type of curriculum, tenure status, and teaching experience) were identified through a search of the literature. However, the path analysis revealed some interesting patterns with respect to the indirect influences of these external variables. For example, the path analysis showed a strong relationship between tenure status, the type of curriculum, and teaching experience and behavioral beliefs. In addition, there was a fairly strong relationship between the type of curriculum and normative beliefs, as well as between tenure status and control beliefs.

This study illuminated several dynamic findings that may influence the use of service learning pedagogy by nursing faculty. The power of the model lies in the 
extent to which it identifies salient determinants of faculty behavior that may, in turn, become targets of faculty change efforts. 


\section{REFERENCES}

American Association of Colleges of Nursing (AACN). (1999). Nursing education's agenda for the $21^{\text {st }}$ century. Retrieved April 1, 2006 from http://www.aacn.nche.edu/Publications/positions/nrsgedag.htm

American Association of Colleges of Nursing (AACN). (2005). Procedures for accreditation of baccalaureate and graduate nursing programs. Retrieved April 1, 2006 from http://www.aacn.nche.edu/Accreditation/procrevd.htm

American Association of Colleges of Nursing (AACN). (2005). Faculty shortage in baccalaureate and graduate nursing programs: Scope of the problem and strategies for expanding the supply. Retrieved April 1, 2006 from http://www.aacn.nche.edu/Media/shortageresource.htm

Abes, E., Jackson, G., \& Jones, S. (2002). Factors that motivate and deter faculty use of service-learning. Michigan Journal of Community Service Learning, 9(1), 5-17.

Ajzen, I. (1991). The theory of planned behavior. Organizational Behavior and Human Decisions Processes, 50, 179-211.

Ajzen, I. (2004). Icek Ajzen Homepage. Retrieved April 1, 2006 from: http://wwwunix.oit.umass.edu/ aizen/

Ajzen, I., \& Fishbein, M. (1980). Understanding attitudes and predicting social behavior. Englewood Cliffs, N.J.: Prentice-Hall, Inc.

Astin, A.W., \& Sax, L.J. (1998). How undergraduates are affected by service participation. Journal of College Student Development, 39(3), 251-263.

Bailey, P., Carpenter, D., \& Harrington, P. (2002). Theoretical foundations of service learning in nursing education. Journal of Nursing Education, 41(10), 433-436.

Beck, E., \& Ajzen, I. (1991). Predicting dishonest actions using the theory of planned behavior. Journal of Research in Personality, 25(3), 285-301.

Ben-Zur, H., Yagil, D., \& Spitzer, A. (1999). Evaluation of an innovative curriculum: nursing education in the next century. Journal of Advanced Nursing, 30(6), 1432-1440.

Berkowitz, B. (2002). Caring and community: Concepts and models for servicelearning in nursing. Journal of Nursing Education, 41(10), 462-472.

Boyer, E. L. (1990). Scholarship reconsidered: Priorities of the professoriate. Princeton, N.J.: The Carnegie Foundation for the Advancement of Teaching. 
Bragg, N. J. (2000). Faculty engagement in service learning. (Doctoral dissertation, Illinois State University, 2000). Dissertation Abstracts International, 61, 4272 .

Bringle. R. G., \& Hatcher, J. A. (1995). A service-learning curriculum for faculty. Michigan Journal of Community Service Learning, 2, 114-122.

Bringle, R. G., \& Hatcher, J. A. (1999). Reflection in service learning: making meaning of experience. Educational Horizons, 77(4), 179-85.

Bringle, R. G, \& Hatcher, J. A. (2000). Institutionalization of service learning in higher education. The Journal of Higher Education, 71(3), 273-296.

Campus Compact. Retrieved April 1, 2006 from http://www.compact.org/faqs/sldefinitions.html

Cohen, S. S., \& Milone-Nuzzo, P. (2001). Advancing health policy in nursing education through service learning. Advances in Nursing Science, 23(3), 2840.

Conatser, P., Block, M., \& Lepore, M. (2000). Aquatic instructors' attitudes toward teaching students with disabilities. Adapted Physical Activity Quarterly, 17, 197-207.

Crawley, F. E. (1990). Intentions if science teachers to use investigative teaching methods: A test of the theory of planned behavior. Journal of Research in Science Teaching, 27(7), 685-697.

Crawley, F. E., \& Koballa, T. R. (1992). Hispanic-American students' attitudes toward enrolling in high school chemistry: A study of planned behavior and beliefs-based change. Hispanic Journal of Behavioral Sciences, 14(4), 469486.

Davis, L. E., Ajzen, I., Saunders, J., \& Williams, T. (2002). The decision of African American students to complete high school: An application of the theory of planned behavior. Journal of Educational Psychology, 94(4), 810-819.

Dee, J. R., Henkin, A. B., \& Pell, S. W. (2002). Support for innovation in site based managed schools: Developing a climate for change. Educational Research Quarterly, 27(4), 36-49.

Dey, E. L. (1997). Working with low response rates. The efficacy of weighting adjustments. Research in Higher Education, 38(2), 215-227. 
Driscoll, A. (2000). Studying faculty and service-learning: Directions for inquiry and development. Michigan Journal of Community Service Learning, Fall Special Issue, 35-41.

Euster, G. L., \& Weinbach, R.W.(1994). Faculty rewards for community service activities: An update. Journal of Social Work Education, 30(3), 317-325.

Faulkner, G., \& Reeves, C. (2000). Primary school student teachers' physical selfperceptions and attitudes toward teaching physical education. Journal of Teaching in Physical Education, 19, 311-324.

Folsom-Meek, S. L., \& Rizzo, T. L. (2002). Validating the physical educators' attitude towards teaching individuals with disabilities III (PEATID III) survey for future professionals. Adapted Physical Activity Quarterly, 19, 141-151.

Gall, M. D., Gall, J. P., \& Borg, W. R. (1999). Applying educational research: A practical guide. New York: Longman.

Gall, M. D., Gall, J. P., \& Borg, W. R. (2003). Educational research: An introduction. Boston, MA: Allyn and Bacon, Inc.

Gelmon, S. B., Holland, B. A., Seifer, S. D., Shinnamon, A., \& Connors, K. (1998). Community-university partnerships for mutual learning. Michigan Journal of Community Service Learning, 5, 97-107.

Gray, M. J., Ondaatje, E. H., Fricker, R. D., \& Geschwind, S. A. (2000). Assessing service-learning. Results from a survey of Learn and Serve America Higher Education. Change, 30-39.

Hammond, C. (1994). Integrating service and academic study: Faculty motivation and satisfaction on Michigan higher education. Michigan Journal of Community Service Learning, 1, 21-28.

Hamner, J. B., Wilder, B., Avery, G., \& Byrd, L. (2002). Community-based service learning in the engaged university. Nursing Outlook, 50(2), 67-70.

Haney, J. J., Czerniak, C. M., \& Lumpe, A. T. (1996). Teacher beliefs and intentions regarding the implementation of science education reform strands. Journal of Research in Science Teaching, 33(9), 971-993.

Haney, J. J., \& McArthur, J. (2002). Four case studies of prospective science teachers' beliefs concerning constructivist teaching practices. Science Education, 86, 783- 789. 
Harakeh, Z., Scholte, R. H., Vermulst, A. A., de Vries, H., \& Engels, R. C. (2004). Parental factors and adolescent's smoking behavior: An extension of the theory of planned behavior. Preventive Medicine, 39(5), 951-961.

Hawks, J. (1999). Organizational culture and faculty use of empowering teaching behaviors in select schools of nursing. Nursing Outlook, 47(2), 67-73.

Hayden, M. H. (2004). Implementation of service learning in higher education courses: Perceptions of faculty. Unpublished doctoral dissertation, Florida International University, Miami, Florida.

Hinck, S. S., \& Brandell, M. E. (2000). The relationship between institutional support and campus acceptance of academic service learning. American Behavioral Scientist, 43(5), 868-881.

Holland, B. A. (1999). Factors and strategies that influence faculty involvement in public service. Journal of Public Service and Outreach, 4(1), 37-43.

Hunt, R. (2002). Service-learning: Curricular applications in nursing. Journal of Nursing Education, 41(10), 463-464.

Jöreskog, K. G., \& Sörbom, D. (1989). LISREL 7: A guide to the program and applications (2nd ed.). Chicago: Statistical Package for the Social Sciences, Inc.

Lumpe, A. T., Haney, J. J., \& Czerniak, C. M. (1998). Science teacher beliefs and intentions regarding the use of cooperative learning. School Science and Mathematics, 98(3), 123-136.

Martin, C. (1994). Faculty perceptions toward service learning within a large public university. (Doctoral dissertation, Pepperdine University). Dissertation Abstracts International, 55, 04.

Martin, J. J., Kulinna, P. H., Eklund, R., \& Reed, B. (2001). Determinants of teachers' intentions to teach physically active physical education classes. Journal of Teaching in Physical Education, 20, 129-143.

Matteson, P. S. (2000). What is community-based education? Implementing community based education in the undergraduate nursing curriculum (pp. 511).Washington, DC: American Association of Colleges of Nursing.

Mertler, C. A., \& Vannatta, R.A. (2002). Advanced and multivariate statistical methods. Practical application and interpretation. Los Angeles: Pyrczak Publishing. 
Munro, B. H. (2005). Statistical methods for health care research. Philadelphia: Lippincott, Williams, and Wilkins.

Power Analysis and Sample Size (PASS). (2002). Retrieved April 1, 2006 from http://www.ACSS.com/pass.html

Pedhazur, E. J. (1981). Multiple regression in behavioral research: Explanation and prediction. Fort Worth: Holt Rinehart and Winston, Inc.

Peterson, S. J., \& Schaffer, M. J. (1999). Service-learning: A strategy to develop group collaboration and research skills. Journal of Nursing Education, 38(5), 208-214.

Pribbenow, D.A. (2002). Exploring the impact of innovative pedagogy on faculty work: The case of service learning. Dissertation Abstracts International, 63, 2813.

Price, J. (2003). Faculty use of service: Learning within the college of agriculture and natural resources at Michigan State University. Dissertation Abstracts International, 64(08), 3587. (UMI No. 3100488).

Robinson, G., \& Barnett, L. (1996). Service learning and community colleges: Where we are. AACN Survey Report. Washington, DC: American Association of Community Colleges.

Rye, B. J., Fisher, W. A., \& Fisher, J. D. (2001). The theory of planned behavior and safer sex behaviors of gay men. AIDS and Behavior, 5(4), 307-317.

Schaefer, K. M., \& Zygmont, D. (2003). Analyzing the teacher style of nursing faculty: Does it promote a student centered or teacher centered learning environment? Nursing Education Perspectives, 24(5), 238-245.

Seifer, S. (2006). Community campus partnerships for health organization. Retrieved April 1, 2006 from: http://depts.washington.edu/ccph/servicelearningres.html

Seifer, S. D., \& Vaughn, R. L. (2002). Partners in caring and community service learning in nursing education. Journal of Nursing Education, 41(10), 437-439.

Tabachnick, B.G., \& Fidell, L. S. (2001). Using multivariate statistics. Boston, MA: Allyn and Bacon.

The $4^{\text {th }}$ Report of the Pew Health Professions Commission. (1998). Recreating health professions practice for a new century. Retrieved April 1, 2006 from http://www.futurehealth.ucsf.edu/press_releases/regnews.html 
The Johnson Foundation (1989). Wingspread principles of good practice for combining service and learning. Retrieved April 1, 2006 from http://www.tcc.edu/students/specialized/civic/servicelearning/principles.htm

Thousand, J. S., \& Burchard, S. (1990). Social integration: Special education teachers' attitudes and behaviors. American Journal of Mental Retardation, 94(4), 407- 419.

Ward, K. (1998). Addressing academic culture: Service-learning, organizations, and faculty work. New Directions for Teaching and Learning, 73, 73-80. 
Appendix A

Group Interview Consent Form 


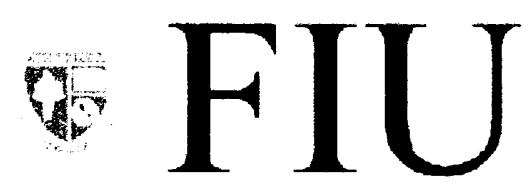

Flor da Inter lational Inistersit?

Dear research participant,

My name is Margaret Bagnardi and I am an Ed. D. candidate from Florida International University College of Education. My dissertation is a study of nursing faculty motivation to use service learning, and I am conducting group interviews to explore the factors that motivate and deterrent faculty use of service learning. The information that I receive from the group interviews will assist me in the development of an instrument for the study.

Your participation and valuable input would be greatly appreciated. The discussion will last approximately 45 - 60 minutes and it will be audio recorded. Anonymity will be ensured by identifying responses by an assigned number rather than by name. The tapes will be transcribed and evaluated for themes. Copies of the transcribed audiotape and the results of the follow up quantitative study will be made available to you if so desired, and upon completion of the study, the tapes will be destroyed.

Your consent to be a research participant is strictly voluntary, and you may decline to participate at any time. Any information that you provide will be held in full confidence. If you have any comments or questions, please fell free to contact myself (mbagnardi@mail.barry.edu, 305-899-3834), one of my co-chairs, Dr. Linda Blanton (Linda.Blanton@fiu.edu), or Dr Ann Nevin (Ann.Nevin( of the Florida International University Institutional Review Board, Dr Jonathan Tubman (Johnathan. Tubman (a)fiu.edu, 305-348-3024).

Thank you for your support!

Respectfully, 
Appendix B

Cover Letter for Pilot Test 


\section{\&

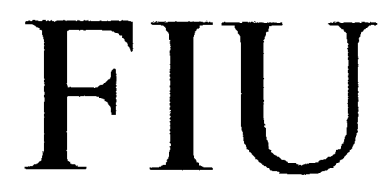

Flor:da Int:reational l nniversit!

Dear Nurse Faculty Member,

Your participation in this research project would be greatly appreciated! My name is Margaret Bagnardi, and I am a doctoral candidate from Florida International University College of Education, and a nursing faculty member at another university in South Florida. My dissertation is a study of nursing faculty motivation to use service learning. Recently I visited your institution and conducted a group interview of several undergraduate faculty members to assist in the creation of this survey. The attached survey contains questions written specifically for nurse educators who teach in undergraduate programs. Completing the survey will take approximately 20 minutes. The information gathered from this survey will help build on prior research pertaining to the use of service learning in nursing education and help guide curricular changes for the $2 \mathrm{I}^{\text {st }}$ century.

Your consent to be a research participant is strictly voluntary, and you may decline to participate at any time. Any information that you provide will be held in full confidence. There will be no indicator on the survey to identify you, only the institution from which the survey was returned from. Any published results of the research will be reported in aggregate, and no personal identifiers will be used. Data collected will be secured in a locked file cabinet in the researcher's office.

Your participation in this study is important. If you have any questions or comments regarding this study or your participation in the study, you may contact me, Margaret Bagnardi, at 954-680-8935, (mbagnardi@mail.barry.edu), the co-chairs of my dissertation committee, Dr Linda Blanton (Linda.Blanton(afiu.edu), or Dr Ann Nevin (Ann.Nevin( $\underline{\text { fiu.edu}}$ ), or the chairperson of the Institutional Review Board at Florida International University, Dr Jonathan Tubman, 305-348-302, (Jonathan.Tubman(wfiu.ed). Thank you for your support!

Respectfully,

Margaret Bagnardi 
Appendix C

Cover Letter for Survey 


\section{.

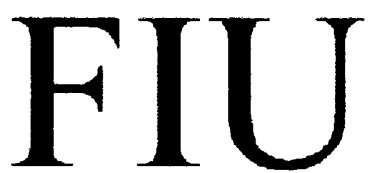

Flor da Intirnational I Iniversil!

Dear nurse faculty member,

Your participation in this research project would be greatly appreciated! My name is Margaret Bagnardi, and I am a doctoral candidate from Florida International University College of Education, and a nursing faculty member at another university in South Florida. My dissertation is a study of nursing faculty motivation to use service learning. The attached survey contains questions written specifically for nurse educators who teach in undergraduate programs. The information gathered will help build on prior research pertaining to the use of service learning in nursing education and help guide curricular changes for the $21^{\text {st }}$ century. Completing the survey will take approximately 15 minutes, and for each completed and returned survey I will donate $\$ 1$ to the American Heart Association.

Your consent to be a research participant is strictly voluntary, and you may decline to participate at any time. Any information that you provide will be held in full confidence. There will be no indicator on the survey to identify you, only the institution from which the survey was returned from. Any published results of the research will be reported in aggregate, and no names will be used in the study. Data collected will be secured in a locked file cabinet in the researcher's office.

If you have any questions or comments regarding this study or your participation in the study, you may contact me, Margaret Bagnardi, at 954-680-8935, (mbagnardi@mail.barry.edu), the co-chairs of my dissertation committee, Dr Linda Blanton (Linda.Blanton@fiu.edu), or Dr Ann Nevin (Ann.Nevin@fiu.edu), or the chairperson of the Institutional Review Board at Florida International University, Dr Jonathan Tubman, 305348-302, (Jonathan.Tubman@fiu.ed).

Thank you in advance for your support!

Respectfully, 
Appendix D

Survey Instrument 


\section{FIU}

Flor da Inter ationd l Iniversits

\section{SERVICE LEARNING QUESTIONAIRE FOR NURSE FACULTY}

\section{STATUS DATA:}

Age

Years of experience teaching in higher education

Highest nursing degree attained:

a $\mathrm{PhD}$

- DNS

- MSN

$\square$ BSN
Tenure status:

$\square$ Tenured

$\square$ Not tenured, on tenure track

$\square$ Not tenured

Degrees held outside of nursing (EdD, MBA, etc):

How many education classes, conferences, or workshops on service learning have you attended in the past five years?

Based on the following definition:

A community based curriculum is a type of nursing education curriculum characterized by all of the following:

a) student are prepared to practice nursing in a multitude of settings in the community

b) there is a focus on partnerships with the community

c) the care of the individual, family, and community (wherever that may be) is incorporated into the coursework.

Do you teach in a community based curriculum? Yes No

If yes, how long have you taught in a community based curriculum?

Please answer the survey questions based on the following definition of service learning:

Service learning is a structured learning experience characterized by all of the following: a) learning objectives that meet the needs of the student, the community, and the profession of nursing,

b) structured time for student reflection on the experience from a personal, global, and professional perspective,

c) enhancement of the student's sense of civic responsibility and professionalism in nursing.

How many times do you plan to use service learning in the current academic school year? 


\section{$\underline{\text { Instructions }}$}

The following questionnaire uses a 7-point rating scale:

$\begin{array}{ccccccccc}\text { Bad } & \text { I } & 2 & 3 & 4 & 5 & 6 & 7 & \text { Good } \\ & \text { Extremely } & \text { Quite } & \text { Slightly } & \text { Neither } & \text { Slightly } & \text { Quite } & \text { Extremely } & \end{array}$

Please circle the number that best describes your opinion.

For me, using service learning in a course in the current academic school year is:

$\begin{array}{lllllllll}\text { 1. Boring } & 1 & 2 & 3 & 4 & 5 & 6 & 7 & \text { Interesting } \\ \text { 2. Costly } & 1 & 2 & 3 & 4 & 5 & 6 & 7 & \text { Affordable } \\ \text { 3. Useless } & 1 & 2 & 3 & 4 & 5 & 6 & 7 & \text { Useful } \\ \text { 4. Inappropriate } & 1 & 2 & 3 & 4 & 5 & 6 & 7 & \text { Appropriate } \\ \text { 5. Time consuming } & 1 & 2 & 3 & 4 & 5 & 6 & 7 & \text { Time saving } \\ \text { 6. Unimaginative } & 1 & 2 & 3 & 4 & 5 & 6 & 7 & \text { Creative } \\ \text { 7. Unsuccessful } & 1 & 2 & 3 & 4 & 5 & 6 & 7 & \text { Successful } \\ \text { 8. Impractical } & 1 & 2 & 3 & 4 & 5 & 6 & 7 & \text { Practical } \\ \text { 9. Complex } & 1 & 2 & 3 & 4 & 5 & 6 & 7 & \text { Simple } \\ \text { 10. Difficult } & 1 & 2 & 3 & 4 & 5 & 6 & 7 & \text { Easy } \\ \text { 11. Unsafe } & 1 & 2 & 3 & 4 & 5 & 6 & 7 & \text { Safe }\end{array}$

12. I plan to use service learning in the current academic school year.
Unlikely
2
3
4
5
6
7
Likely

13. I will try to use service learning in the current academic school year.
Unlikely
2
3
4
5
6
$7 \quad$ Likely

14. I aim to use service learning in the current academic school year.
Unlikely 1
2
3
4
5
6
$7 \quad$ Likely 
15. My using service learning in the current academic school year would increase student learning.
Unlikely 1
$2 \quad 3$
4
5
6
7
Likely

16. My using service learning in the current academic school year would make my classes more fun and interesting.
Unlikely
23
$4 \quad 5$
6
$7 \quad$ Likely

17. My using service learning in the current academic school year would take time away from covering important nursing content.

$\begin{array}{llllllllll}\text { Unlikely } & 1 & 2 & 3 & 4 & 5 & 6 & 7 & \text { Likely }\end{array}$

18. Most people who are important to me think that

$\begin{array}{llllllllll}\text { I should not } & 1 & 2 & 3 & 4 & 5 & 6 & 7 & \text { I should }\end{array}$
use service learning in the current academic school year.

19. My colleagues who review my promotion portfolio think that
I should not 1
$2 \quad 3$
45
6
7 I should use service learning in the current academic school year.

20. My administrators think that

$\begin{array}{lllllllll}\text { I should not } & 1 & 2 & 3 & 4 & 5 & 6 & 7 & \text { I should }\end{array}$
use service learning in the current academic school year.

21. My_students think that

$\begin{array}{llllllllll}\text { I should not } & 1 & 2 & 3 & 4 & 5 & 6 & 7 & \text { I should }\end{array}$
use service learning in the current academic school year.

22. It is expected of me to use service learning in the current academic school year.

$\begin{array}{lllllllll}\begin{array}{l}\text { Strongly } \\ \text { disagree }\end{array} & 1 & 2 & 3 & 4 & 5 & 6 & 7 & \begin{array}{c}\text { Strongly } \\ \text { agree }\end{array} \\ \end{array}$

23. The people in my life whose opinion I value would

$\begin{array}{lllllllll}\begin{array}{l}\text { Strongly } \\ \text { disapprove }\end{array} & 1 & 2 & 3 & 4 & 5 & 6 & 7 & \begin{array}{l}\text { Strongly } \\ \text { approve }\end{array} \\ \end{array}$

of my using service learning in the current academic school year.

24. Generally, I comply with the wishes of my nursing faculty colleagues.

$\begin{array}{llllllllll}\begin{array}{l}\text { Strongly } \\ \text { disagree }\end{array} & \mathrm{I} & 2 & 3 & 4 & 5 & 6 & 7 & \begin{array}{l}\text { Strongly } \\ \text { agree }\end{array}\end{array}$


25. It is a professional obligation for me to use service learning in the current academic school year.

$\begin{array}{lllllllll}\begin{array}{l}\text { Strongly } \\ \text { disagree }\end{array} & 1 & 2 & 3 & 4 & 5 & 6 & 7 & \begin{array}{l}\text { Strongly } \\ \text { agree }\end{array}\end{array}$

26. Most people who are important to me use service learning.

$\begin{array}{lllllllll}\begin{array}{l}\text { Completely } \\ \text { false }\end{array} & 1 & 2 & 3 & 4 & 5 & 6 & 7 & \begin{array}{c}\text { Completely } \\ \text { true }\end{array} \\ \end{array}$

27. My prior teachers have influenced my decision to use service learning.

$\begin{array}{lllllllll}\begin{array}{l}\text { Strongly } \\ \text { disagree }\end{array} & 1 & 2 & 3 & 4 & 5 & 6 & 7 & \begin{array}{l}\text { Strongly } \\ \text { agree }\end{array}\end{array}$

28. My parents have influenced my decision to use service learning.
Strongly 1
23
$4 \quad 5$
6
$7 \quad$ Strongly
disagree
agree

29. My religious beliefs influence my decision to use service learning.

$\begin{array}{lllllllll}\begin{array}{l}\text { Strongly } \\ \text { disagree }\end{array} & 1 & 2 & 3 & 4 & 5 & 6 & 7 & \begin{array}{l}\text { Strongly } \\ \text { agree }\end{array}\end{array}$

30. My own philosophy of life influences my decision to use service learning.
Strongly
3
45
6
7
Strongly
disagree agree

31. My personal beliefs influence my decision to use service learning.

$\begin{array}{lllllllll}\begin{array}{l}\text { Strongly } \\ \text { disagree }\end{array} & 1 & 2 & 3 & 4 & 5 & 6 & 7 & \begin{array}{l}\text { Strongly } \\ \text { agree }\end{array}\end{array}$

32. My family influences my decision to use service learning.

$\begin{array}{llllllllll}\begin{array}{l}\text { Strongly } \\ \text { disagree }\end{array} & 1 & 2 & 3 & 4 & 5 & 6 & 7 & \begin{array}{l}\text { Strongly } \\ \text { agree }\end{array}\end{array}$

33. My view of life influences my decision to use service learning.
Strongly
23
4
5
6
7 Strongly
agree

34. For me to use service learning in the current academic school year would be $\begin{array}{llllllllll}\text { Impossible } & 1 & 2 & 3 & 4 & 5 & 6 & 7 & \text { Possible }\end{array}$

35. If I wanted to, I could use service learning in the current academic school year.
Definitely
2
3
4
5
6
7
Definitely
False true 
36. How much control do you believe that you have over using service learning in the current academic school year?

$\begin{array}{lllllllll}\begin{array}{l}\text { No } \\ \text { Control }\end{array} & 1 & 2 & 3 & 4 & 5 & 6 & 7 & \begin{array}{l}\text { Complete } \\ \text { control }\end{array} \\ \end{array}$

37. It is up to me if I use service learning in the current academic school year.

$\begin{array}{lllllllll}\begin{array}{l}\text { Strongly } \\ \text { disagree }\end{array} & 1 & 2 & 3 & 4 & 5 & 6 & 7 & \begin{array}{l}\text { Strongly } \\ \text { agree }\end{array}\end{array}$

38. I have all the resources that I need to use service learning in the current academic school year.

$\begin{array}{lllllllll}\begin{array}{l}\text { Strongly } \\ \text { disagree }\end{array} & 1 & 2 & 3 & 4 & 5 & 6 & 7 & \begin{array}{l}\text { Strongly } \\ \text { agree }\end{array}\end{array}$

39. Professional regulations make it difficult for me to use service learning in the current academic school year.
Strongly $1 \quad 2$
$\begin{array}{lll}2 & 3 & 4\end{array}$
5
6
$7 \quad$ Strongly
disagree
agree

40. The prescribed curriculum in the nursing program makes it difficult for me to use service learning.

$\begin{array}{llllllllll}\begin{array}{l}\text { Strongly } \\ \text { disagree }\end{array} & 1 & 2 & 3 & 4 & 5 & 6 & 7 & \begin{array}{l}\text { Strongly } \\ \text { agree }\end{array}\end{array}$

41. I have the knowledge to use service learning.

$\begin{array}{llllllllll}\begin{array}{l}\text { Strongly } \\ \text { disagree }\end{array} & 1 & 2 & 3 & 4 & 5 & 6 & 7 & \begin{array}{l}\text { Strongly } \\ \text { agree }\end{array}\end{array}$

42. The university mission supports the use of service learning.

$\begin{array}{lllllllllll}\begin{array}{l}\text { Strongly } \\ \text { disagree }\end{array} & 1 & 2 & 3 & 4 & 5 & 6 & 7 & \begin{array}{l}\text { Strongly } \\ \text { agree }\end{array}\end{array}$

43. There is adequate funding support for me to use service learning in the current academic school year.
Strongly
2
34
5
6
7 Strongly
agree
disagree

44. There is adequate release time for me to use service learning in the current academic school year.

Strongly

$2 \quad 3 \quad 4$

5

6

7 Strongly

disagree

1

(2)

agree 
45. There is adequate clerical support for me to use service learning in the current academic school year.
Strongly 1
2
3
4
5
6
7
Strongly
disagree
agree

46. There are adequate mechanisms in place to ensure the safety of the students during a service learning activity.
Strongly $1 \quad 2$
34
5
6
7 Strongly
disagree
agree

47. There is adequate reimbursement of travel expenses for me to use service learning in the current academic school year.

$\begin{array}{lllllllll}\begin{array}{l}\text { Strongly } \\ \text { disagree }\end{array} & 1 & 2 & 3 & 4 & 5 & 6 & 7 & \begin{array}{l}\text { Strongly } \\ \text { agree }\end{array}\end{array}$

48. I can safely monitor my students during a service learning activity.

$\begin{array}{lllllllll}\begin{array}{l}\text { Strongly } \\ \text { disagree }\end{array} & 1 & 2 & 3 & 4 & 5 & 6 & 7 & \begin{array}{l}\text { Strongly } \\ \text { agree }\end{array}\end{array}$

49. I can adequately evaluate my students during a service learning activity.

$\begin{array}{lllllllll}\begin{array}{l}\text { Strongly } \\ \text { disagree }\end{array} & 1 & 2 & 3 & 4 & 5 & 6 & 7 & \begin{array}{l}\text { Strongly } \\ \text { agree }\end{array}\end{array}$


Appendix E

Survey Reminder 


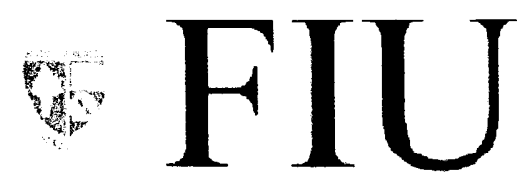

Flor da Inter lational Iniversit

You should have recently received a survey from me pertaining to nursing faculty use of service learning. If you have completed and returned it to me, 1 would like to send my sincere thanks. This dissertation process has been quite a journey! If you have not had the chance to complete the brief survey, I would ask that you please consider doing so. You input would be greatly appreciated!

Have a wonderful academic year!

Respectfully,

Margaret Bagnardi, MSN, ARNP

Doctoral Candidate

Assistant Professor of Nursing

Barry University School of Nursing 


\section{MARGARET BAGNARDI}

1959

Born in Oneonta, New York

1980

A.S., Nursing

Adirondack Community College

Glens Falls, New York

1980-1983

Registered Nurse

Medical Center Del Oro

Houston, Texas

1983-1985

Registered Nurse

Mary Imogene Bassett Hospital

Cooperstown, New York

1985-1995

Registered Nurse

South Miami Hospital

Miami, Florida

1989-present

Registered Nurse

Memorial Healthcare System

Hollywood, Florida

1990

B.S., Nursing

Florida International University

Miami, Florida

1993

M.S., Nursing

University of Miami

Miami, Florida

1994-present

Assistant Professor of Nursing

Barry University

Miami, Florida 


\section{PUBLICATIONS AND PRESENTATIONS}

Bagnardi, M. G. (2006, April). Developing an instrument to assess nursing faculty intention to use service learning pedagogy. Paper accepted for presentation at American Educational Research Association, San Francisco, CA.

Bagnardi, M.G. (2005). The learning achievement program: Fostering student cultural diversity, Nurse Educator, 30(1), 17-20.

Bagnardi, M.G. (2003, November). Service learning: A tool for student engagement. Paper presentation at the American Association of Colleges of Nursing, Sixth Annual Baccalaureate Education Conference, San Antonio, Texas

Bagnardi, M.G. (2002, November). Learning achievement program: Keeping a culturally diverse face in the classroom. Paper presentation at the American Association of Colleges of Nursing, Fifth Annual Baccalaureate Education Conference, Lake Buena Vista, FL 